\title{
Die Integration des landfremden Adels in die frühneuzeitliche mährische Adelsgesellschaft Rechtsnorm und symbolische Form*
}

\author{
von \\ TOMÁŠ KNOZ
}

Der vorliegende Beitrag kann bei Weitem nicht den Anspruch auf eine komplexe Lösung der keineswegs einfachen Problematik der Integration des landfremden Adels in die adelige Gesellschaft eines bestimmten Landes erheben, in diesem Fall der frühneuzeitlichen Markgrafschaft Mähren. ${ }^{1}$ Zumindest in Ansätzen und anhand einiger miteinander in Zusammenhang stehender Beispiele wollen wir dennoch den Versuch unternehmen, die angesprochene Problematik zu thematisieren, und zwar als Kommunikation zwischen der konkreten Welt der Rechtsnorm und der abstrakten Welt der symbolischen Form. ${ }^{2}$

* Der Beitrag entstand an der Masaryk-Universität (Brno) im Rahmen des Projekts „Centre for Cross-Disciplinary Research into Cultural Phenomena in the Central European History: Image, Communication, Behaviour“, Reg. Nr. GA ČR 14-36521G. Aus dem Tschechischen übersetzt von Thomas Krzenck.

1 Mit der Frage der Integration des „landfremden Adels“ in Böhmen und Mähren hat sich in den zurückliegenden Jahren zumindest peripher bzw. kontextual auch die tschechische Historiografie befasst. Vgl. diesbezüglich u. a. Lenka Boвкová, Cizí šlechta v politickém systému předbělohorských ýech [Der landfremde Adel im politischen System Böhmens in der Zeit vor der Schlacht am Weißen Berg], in: Jiř́ Fák (Hg.), Gryspekové a česká šlechta. Kralovice a poddanská města, Mariánské Týnice 1998, S. 3-17; ZDENĚK POKLUDA, Majetek uherské šlechty v šeských zemích v 15.-20. století [Der Besitz des ungarischen Adels in den böhmischen Ländern im 15.-20. Jahrhundert], in: Časopis Matice moravské 98 (1979), S. 296-325; Tomáš Knoz, Die Integration des Adels schlesischer Herkunft in die Gesellschaft Mährens in der Frühen Neuzeit, in: Jan Harasimowicz/Matthias Weber (Hg.), Adel in Schlesien, Bd. 1: Herrschaft - Kultur Selbstdarstellung (Schriften des Bundesinstituts für Kultur und Geschichte der Deutschen im östlichen Europa 36), München 2010, S. 263-291.

2 Zur Problematik der Geschichte des Adels in Böhmen und Mähren in der Frühen Neuzeit wurden in den letzten Jahren zahlreiche gewichtige Monografien und Aufsätze verfasst. Vgl. u. a. VÁcLAv BƯŽEK, Šlechta v raného novověku v českém dějepisectví devadesátých let [Der Adel in der Frühen Neuzeit in der tschechischen Geschichtsschreibung in den Neunzigerjahren des 20. Jahrhunderts], in: Václav Bưžek/Pavel Král (Hg.), Aristokratické rezidence a dvory v raném novověku (Opera historica 7), České Budějovice 1999, S. 5-28; VÁclav BŮžEK, Majetková skladba šlechty v předbělohorských Čechách [Die Besitzstruktur des Adels in Böhmen vor der Schlacht am Weißen Berg], in: Hospodářské dějiny - Economic history 14 (1986), S. 175-216; Petr MAŤA, Aristokratisches Prestige und der böhmische Adel (1500-1700), in: Frühneuzeit-Info 10 (1999), S. 43-52; Ders., Der Adel aus den böhmischen Ländern am Kaiserhof 16201740. Versuch, eine falsche Frage richtig zu lösen, in: Václav BŮžek/Pavel Král (Hg.), Šlechta v habsburské monarchii a císařský dvůr (1526-1740) (Opera historica 10), Ceské Budějovice 2003, S. 191-233; Ders., Svět české aristokracie (1500-1700) [Die Welt der böhmischen Aristokratie], Praha 2004; VÁclav BỦžEK, Nižší šlechta v politickém 
Die frühneuzeitliche Markgrafschaft Mähren lag geografisch vom damaligen Kurfürstentum Sachsen doch ziemlich weit entfernt, aus diesem Grunde mag eine Analyse der mährischen Adelsgesellschaft im Kontext der Erforschung des geografischen Raumes Sachsen - Böhmen als nicht sehr angemessen erscheinen. Im Falle der hier dargelegten Überlegungen geht es vor allem um eine komparative Fallstudie, die am konkreten Beispiel Mähren versucht, einige Aspekte der Integration des landfremden Adels in die aristokratische Gesellschaft eines anderen konkreten Landes aufzuzeigen und die zugleich den Versuch unternimmt, auf einige allgemeine Aspekte dieses bedeutenden historischen Phänomens hinzuweisen. Auf der anderen Seite jedoch lassen sich unschwer auch einige konkrete Beispiele für die Integration von Repräsentanten des Adels zwischen Sachsen und Mähren finden. Einen derartigen Integrationstyp vermögen die Lebensbahnen von Angehörigen der Generation der Familie Pfefferkorn von Otopach nach 1620 zu verdeutlichen: Während Karl Pfefferkorn von Otopach nach der verlorenen Schlacht am Weißen Berg nach Sachsen emigrierte, wo er auch dank seines literarischen Werkes zu einem der Wortführer der böhmischen Emigration in Pirna avancierte und letztlich zur Integration des böhmischen Zweigs seiner Familie in Sachsen beitrug, erlangte sein Verwandter Georg Pfefferkorn in Diensten Kaiser Ferdinands II. eine einflussreiche Beamtenstellung in Mähren und trug seinerseits zur Integration seines Familienzweigs im Milieu des Beamtenadels in der Markgrafschaft Mähren nach der Schlacht am Weißen Berg bei. ${ }^{3}$

Vermutlich noch exemplarischer ist das Beispiel der mährischen Integration der Familie Haugwitz von Biskupitz. Sofern auf die genealogische und historisch-topografische Literatur Verlass ist, wanderte diese Familie aus dem Meißnischen in die böhmischen Länder ein, und zwar zunächst in die Lausitz. Von hier aus fasste ein Familienzweig in Mähren Fuß, wo die Haugwitz noch in der Ära vor der Schlacht am Weißen Berg nicht allein bedeutende Ländereien erwarben, sondern zugleich auch hohe ständische Ämter bekleideten. ${ }^{4}$ Joachim Haugwitz von Biskupitz stieg an der Wende vom 16. zum 17. Jahrhundert schließlich sogar in das höchste Amt im Lande auf, jenes des mährischen Landeshauptmanns, ${ }^{5}$ wobei er - der Auffassung einiger Historiker zufolge - in der Zeit der Zuspitzung der politisch-konfessionellen Konflikte im

systému a kultuře předbělohorských Čech [Der niedere Adel im politischen System und der Kultur Böhmens vor der Schlacht am Weißen Berg], Praha 1996; Ders., Rytiŕi renesančních Čech [Die Ritter in Böhmen in der Renaissance], Praha 1995. Hier auch weitere Literaturhinweise.

3 Lenka Boвкоvá, Böhmische Exulanten in Sachsen während des Dreißigjährigen Krieges. Am Beispiel der Stadt Pirna, in: Frühneuzeit-Info 10 (1999), S. 21-29; DiEs., Česká exulantská šlechta v Pirně roku 1629 [Adelige Exulanten aus Böhmen in Pirna im Jahre 1629], in: Folia Historica Bohemica 19 (1998), S. 83-116; Dies., Exulanti z Prahy a severozápadních Čech v Pirně v letech 1621-1639 [Exulanten aus Prag und Nordböhmen in Pirna in den Jahren 1621-1639], Praha 1999. Zur Beamtenkarriere des Georg Pfefferkorn von Otopach vor und nach der Schlacht am Weißen Berg vgl. Tomáš Knoz, Pobělohorské konfiskace. Moravský průběh, středoevropské souvislosti, obecné aspekty (Knižnice Matice moravské 19; Opera Universitatis Masarykianae Brunensis, Facultas philosophica 361), Brno 2006, v. a. S. 594-611. Georg Pfefferkorn von Otopach war nach 1621 einer jener Finanzbeamten, die die Bewertungsprotokolle des konfiszierten adeligen Besitzes verfassten.

4 Josef Pilnáček, Staromoravští rodové [Altmährische Geschlechter], Wien 1930 [Reprint Brno 1972], S. 389.

5 Antonín BočEK, Přehled knížat a markrabat i jiných nejvyšších důstojníků zemských v Markrabství moravském [Übersicht über die Fürsten und Markgrafen sowie weitere oberste Landesbeamte in der Markgrafschaft Mähren], Brno 1850. 


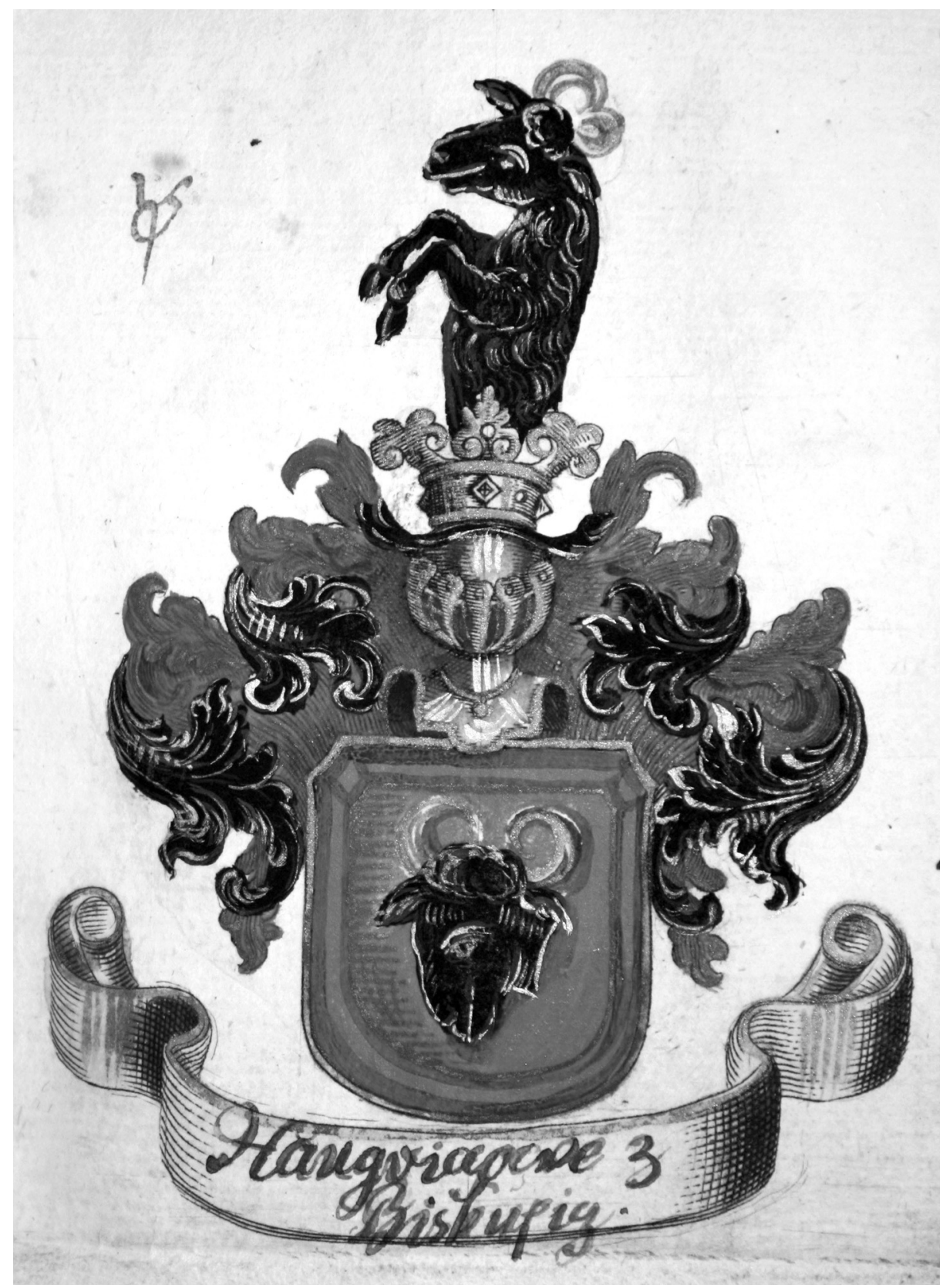

Abb. 1: Wappen der Hangwitz von Biskupitz. Wappenbuch, Mähren, um 1620. 


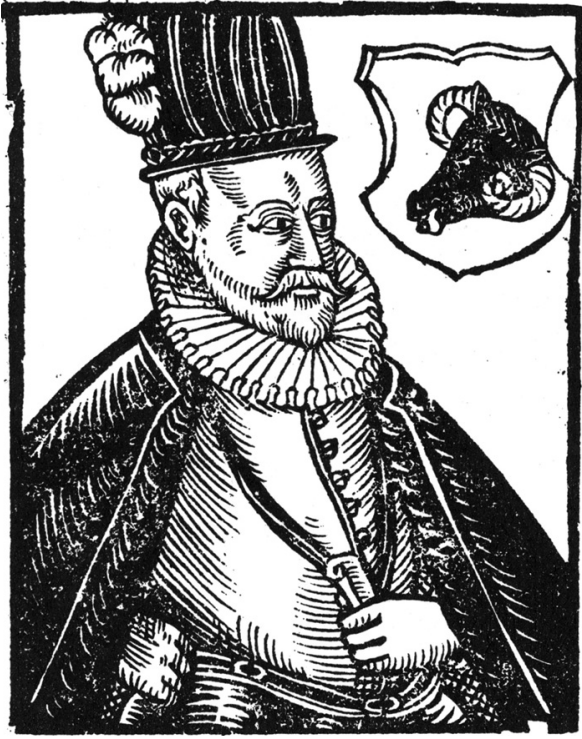

Abb. 2: Joachim Haugwitz von Biskupitz. BARTOLOMÄUS PAPROCKY VON HLOHOL, Zrcadlo slavnébo Margkrabstvi moravského, Olomouc 1593.

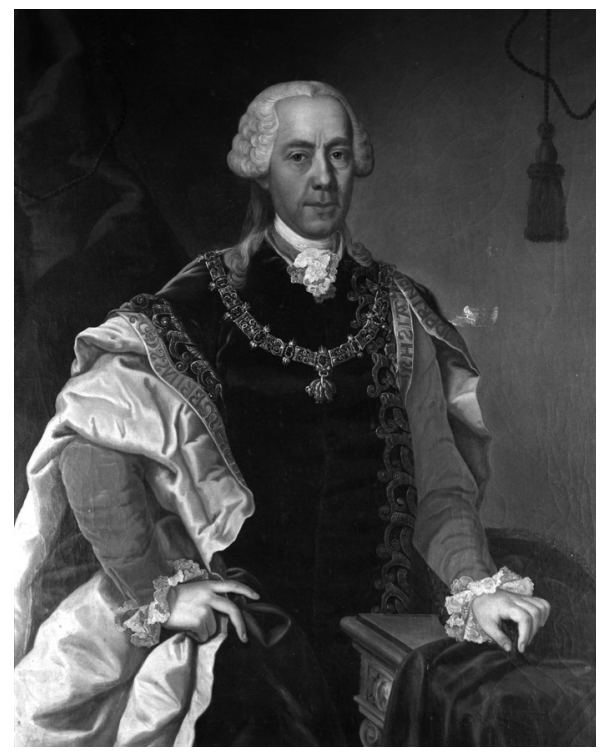

Abb. 3: Friedrich Wilhelm Hangwitz von Biskupitz. Schloss Namiest an der Oslawa.

Lande als gemäßigter Katholik die Rolle einer integrierenden Persönlichkeit auch unter den Angehörigen der konfessionell und politisch zersplitterten ursprünglichen Aristokratie Mährens ausfüllte. ${ }^{6}$ Im Falle der Haugwitz von Biskupitz kam es darüber hinaus auch noch zu einer sekundären Integration in Mähren, als ein Teil der Familie über die Lausitz nach Schlesien gelangte und von hier aus später weiter nach Mähren. Der schlesische Zweig der Haugwitz verwurzelte nachfolgend in der Spätphase der Frühen Neuzeit und im 19. Jahrhundert in Mähren im Bereich der Kultur, was im Übrigen auch - trotz der Peripetien des 20. Jahrhunderts - in Namiest an der Oslawa bis in die Gegenwart fortdauert. ${ }^{7}$

\section{Problembeschreibung}

Eine Definition des Begriffes „Integration des landfremden Adels im Milieu der aristokratischen Gesellschaft eines anderen/benachbarten Landes (Mähren)“ erscheint nicht ganz einfach und eindeutig, zumal es sich um ein bedeutsames Phänomen handelt, das bei der Erforschung der Adelsgesellschaft nicht vergessen werden darf. In den zurückliegenden Jahren schien es möglich den Terminus „Integration des Adels“ eher in einen Zusammenhang mit dem Begriff „Herrscherhof“ zu stellen, und es handelte

6 Josef VÁlka, Dějiny Moravy II: Morava reformace, renesance a baroka [Geschichte Mährens II: Mähren in Reformation, Renaissance und Barock] (Vlastivěda moravská, Země a lid, Nová řada 6), Brno 1995, S. 45-48.

7 Johanna Haugwitz-El Kalak, Die Herrschaft Namiest im Wandel der Zeiten. Ein Spiegelbild europäischer Geschichte, Telč 2013. 
sich folglich um ein Phänomen der schrittweisen Veränderung der Mentalität des Adels in Richtung des „Hofadels“ bzw. (um mit Norbert Elias zu sprechen) der „höfischen Gesellschaft". ${ }^{8}$ Für das Milieu der mitteleuropäischen Gesellschaft darf in diesem Zusammenhang zumindest an die Forschungen von Géza Pálffy, Václav Bůžek, Petr Mała und anderen erinnert werden. ${ }^{9}$ Dieser Typ der Integration spiegelt diejenige Situation wider, in der der Herrscherhof (im hier angedeuteten Kontext der des Kaisers) ein derart attraktives Zentrum der Macht und der Kultur darstellt, dass zahlreiche Angehörige des Adels, die an der Ausübung der Macht und an der Kultur unmittelbar beteiligt sein wollen, hierher strömen. Umgekehrt lässt sich dieses Phänomen aus Sicht des Landes als (in gewissem Umfang) Ausdruck der Desintegration werten.

Sofern wir die Integration des Adels im Land verfolgen wollen, muss das Phänomen des Landes in Mitteleuropa als verfassungsrechtliches, politisches und kulturelles Ganzes definiert werden, das relativ geschlossen erscheint und in dem der Adel die Elite verkörpert, die auf das Land ausgerichtet ist und die als entscheidender Faktor agiert (eine derartige Definition des Landes versuchte in den zurückliegenden Jahren ein Wissenschaftlerteam des - in deutscher Übersetzung - „Forschungszentrums für die Geschichte Mitteleuropas: Länder, Quellen, Kultur“ zu formulieren). ${ }^{10}$ Neben dem ursprünglichen Adel, der seit Generationen mit dem Land verbunden ist (rechtlich durch den Terminus des „alteingesessenen Adels“ definiert, der sich sui generis als (Mit)Besitzer des Landes - neben dem Landesherrn - betrachtet), versucht sich auch der neu ins Land strömende Adel hier einzubringen. ${ }^{11}$ Wenngleich dieser Typ der

8 Norbert Elias, Die höfische Gesellschaft (Soziologische Texte 54), Neuwied/Berlin 1969; Ders., Über den Prozeß der Zivilisation. Soziogenetische und psychogenetische Untersuchungen, Frankfurt a. M. 1993.

9 VÁClav BŮŽEK/GÉZA PÁlfFY, Integrace šlechty z českých a uherských zemí ke dvoru Ferdinanda I. [Die Integration des Adels aus den böhmischen und ungarischen Ländern am Hofe Ferdinands I.], in: Český časopis historický 101 (2003), S. 542-581; GÉzA PÁlfFy, Medien der Integration des ungarischen Adels in Wien im 16. und 17. Jahrhundert, in: Collegium-Hungaricum-Studien 1 (2002), S. 61-98.

10 Tomáš Knoz, Natus Moravus, linguae Bohemus. Nation, State, Language and Culture in Early Modern Moravia, in: Historica. Historical Sciences in the Czech Republic 9 (2002), S. 41-59; VÁlKa, Dějiny Moravy II (wie Anm. 6), S. 245.

11 Einen zeitgenössischen Überblick des mährischen Adels lieferte Bartoloměj Paprocký z Hlohol, ein ursprünglich aus Polen stammender Adeliger, der am Ende des 16. Jahrhunderts in Diensten des Olmützer Bischofs Stanislaus Pavlovsky stand. BARTOLOMĚJ Paprocký z Hlohol, Zrcadlo slavného Markrabství moravského [Spiegel der berühmten Markgrafschaft Mähren], Olomouc 1593 [Reprint Ostrava 1993]. Zum Werk des Bartoloměj Paprocký vgl. Karel Krejčí, Bartoloměj Paprocki z Hlohol a Paprocké Vúle. Život - dílo - forma a jazyk [Bartoloměj Paprocki von Hlohol und Paprocké Vúle. Leben - Werk - Form und Sprache], Praha 1946; Josef Jireček, Bartoloměj Paprocký z Hlohol a Paprocké Vůle a spisovatelská činnost jeho [Bartoloměj Paprocký von Hlohol und Paprocké Vůle und sein schriftstellerisches Werk], in: Časopis českého musea 40 (1866), S. 13-16; KAREL Krejčí, Bartoloměj Paprocký z Hlohol a Paprocké Vůle [Bartoloměj Paprocký von Hlohol und Paprocké Vůle], in: Bartoloměj Paprocký/ Josef Polišenský, Zrcadlo Čech a Moravy, Praha 1941, S. 239-253; EduARd Petrư, Autor dvou literatur. Bartoloměj Paprocký z Hlohol a Paprocké Vůle [Autor zweier Literaturen. Bartoloměj Paprocký von Hlohol und Paprocké Vủle], in: Ders. (Hg.), Bartoloměj Paprocký z Hlohol a Paprocké Vủle. O válce turecké a jiné př́běhy, Praha 1982, S. 7-10; Ders./Ivo Hlobil, Humanismus a raná renesance na Moravě [Humanismus und Frührenaissance in Mähren], Praha 1992, S. 54-59; Tomáš Sterneck, Bartoloměj Paprocký z Hlohol a královské město Brno [Bartoloměj Paprocký von 
Integration in Milieu, Zeit und individuellen Herangehensweisen wandelbar erscheint, gelten bestimmte allgemeine Prinzipien. Sofern der Herrscher den neu ankommenden Adel, in welcher Form auch immer, in das Leben im Lande einzubeziehen suchte (familiär, ökonomisch, kulturell, politisch), musste er bestimmte rechtliche Bedingungen mit Blick auf die verfassungsmäßigen Gewohnheiten im entsprechenden Land erfüllen, wobei es eine ganze Reihe von Varianten gab: Als eine solche der nicht vollständigen Integration darf die Situation angesehen werden, wenn der neu angekommene Adelige im Lande Grundbesitz erwarb und die rechtlichen Integrationsbedingungen erfüllte, wobei dessen ungeachtet er sich politisch und kulturell nicht dem Niveau des Landes anpasste, sondern z. B. eher dem kaiserlichen Hofe außerhalb des Landes. Die Integrationsprinzipien umfassten - im Einklang mit der zeitgenössischen Mentalität für gewöhnlich sowohl konkrete rechtliche und politische als auch symbolische und emblematische Formen. Beide Prinzipien waren dabei innerlich verbunden und durchdrangen sich gegenseitig. ${ }^{12}$

Im tschechischen Allgemeinbewusstsein und im hohen Maße auch in der historiografischen Literatur hat sich seit dem 19. Jahrhundert die Auffassung verbreitet, dass die Integration des landfremden Adels in Zusammenhang mit der Schlacht am Weißen Berg steht, dass diese einen gewaltsamen bzw. zumindest konfessionell-politisch geprägten Charakter besaß und dass diese zugleich eine Zerschlagung der ursprünglichen Adelsgesellschaft, die zum einen von der mittelalterlichen Tradition und zum anderen vom „Königtum beiderlei Volks“ der nachhussitischen Epoche ausging, bedeutete. Der erwähnte „Mythos Weißer Berg“ (Bílá Hora) wurde zwar in der modernen Historiografie wiederholt einer Kritik unterschiedlicher Art unterzogen (mit ironischem Unterton Jiří Rak, ${ }^{13}$ aus prägnant historisch-philosophischer Perspektive Josef Petráň ${ }^{14}$ ) und spielt innerhalb der jüngeren Generation tschechischer Historiker keine bedeutsame Rolle, als einer der ersten meldete sich jedoch Josef Válka mit einer kritischen Wertung zu Wort. Dieser wies darauf hin, dass die neuzeitliche Integration des landfremden Adels im Milieu Böhmens und Mährens (Schlesien muss an dieser Stelle als ein sehr eigener Sonderfall außerhalb der Betrachtung bleiben) bei Weitem nicht erst mit der Schlacht am Weißen Berg und dem Dreißigjährigen Krieg einsetzte, sondern vielmehr bereits im Augenblick der Thronbesteigung der Habsburger in Böhmen und der personellen Vereinigung der Funktion des römischen Kaisers, des Erzherzogs von Österreich, des böhmischen Königs und des Markgrafen von Mähren. Dies ließ Angehörige des Reichs- und anderen Adels in die österreichischen und böhmischen Länder strömen, die sich primär im Milieu des Wiener (und für eine gewisse Zeit auch des Prager) Kaiserhofes und sekundär wirtschaftlich, familiär und anderweitig im Milieu der aristokratischen Gesellschaften der einzelnen Länder innerhalb der wer-

Hlohol und die königliche Stadt Brünn], in: Brno v minulosti a dnes 15 (2001), S. 133151.

12 KNOz, Integration des Adels schlesischer Herkunft (wie Anm. 1), S. 263-291.

13 JiŘí Rak, Bývali Čechové. České historické mýty a stereotypy [Sie waren Tschechen. Tschechische historische Mythen und Stereotypen], Praha 1994; Ders., Stereotyp Němce v českém historickém vědomí [Der Stereotyp des Deutschen im tschechischen historischen Bewusstsein], in: Dějiny a současnost 12 (1990), Nr. 3, S. 34-37.

14 Josef Petráň, Na téma mýtu Bílé hory [Zum Thema des Mythos Weißer Berg], in: Zdeňka Hledíková (Hg.), Traditio et cultus. Miscelanea Historica Bohemica. Miloslao Vlk archiepiscopo Pragensi ab eius collegis amicisque ad annum sexagesimum dedicata, Praha 1993, S. 141-162; Josef Petráň, Lid a národ v pobělohorském labyrintu [Volk und Nation im Labyrinth der Zeit vor der Schlacht am Weißen Berg], in: František Graus (Hg.), Naše živá a mrtvá minulost, Praha 1968, S. 72-106. 
denden Habsburgermonarchie, einschließlich Böhmens und Mährens, zu integrieren begannen bzw. als es zu einem Integrationstransfer innerhalb dieser Länder kam, so etwa zwischen der Steiermark, Österreich und Mähren (Fall des Reichspfennigmeisters Stephan Schmidt von Freihofen). ${ }^{15}$

Im erwähnten Kontext nahm Mähren in bedeutendem Umfang eine Sonderstellung ein. In der Vergangenheit haben zahlreiche Historiker sich bemüht, diese zu beschreiben, am methodologisch interessantesten und sachlich genauesten hat sich vermutlich der bereits mehrfach erwähnte Josef Válka mit dieser Frage befasst. Seine Herangehensweisen spiegeln sich in gewissem Sinne auch in den Debatten um die Bezeichnung der bereits erwähnten Forschungsrichtung wider, in denen es um die symbolische Charakterisierung Mährens als kulturelle Brücke bzw. als „offenes Land“ geht. ${ }^{16}$ Mähren spielte im frühneuzeitlichen Europa eine interessante Rolle als Land ohne Herrscher und Herrscherhof; als Landesherr fungierte der Markgraf von Mähren, doch bekleidete diese Würde seit 1411 der böhmische König und seit 1526 als solche wiederum der römische Kaiser aus der Familie der Habsburger.

Es fehlte also in Mähren ein integrierender Hof, und die Herrscherhöfe in Buda, Wien bzw. Prag spielten in ihrer Zeit für die Angehörigen des mährischen Adels eine etwas andere Rolle als der das natürliche Zentrum des Landes bildende Hof. Die katholische Kirche spielte zwar auch in der nachhussitischen Ära eine wesentlich stärkere Rolle als in Böhmen, dennoch fungierte sie nicht als einigender Faktor und der Hof der Olmützer Bischöfe (in seinem geistlich-bischöflichen und profan-fürstlichen Element) konnte aus diesem Grunde diese Rolle auch nur in begrenztem Umfang erfüllen. ${ }^{17}$ Die landesherrlichen/königlichen Städte waren im Untersuchungszeitraum

15 Josef VÁlKa, Česká společnost v 15.-18. století [Die tschechische Gesellschaft im 15.18. Jahrhundert], I: Předbělohorská doba, Praha 1972 sowie II: Bělohorská doba. Kultura manýrismu, Praha 1983, S. 69-74. Der Reichspfennigmeister Stephan Schmidt von Freihofen war über die ganze Zeit der 20er-Jahre in Mähren einer der wenigen Lutheraner, die für ihre dem Kaiser geleisteten Dienste konfiszierte Güter erhielten, ohne dass auf sie Druck ausgeübt worden wäre, zum Katholizismus zu konvertieren. 1628 änderte sich die Situation plötzlich und Stephan Schmidt wurde befohlen, sein Eigentum zu verkaufen und das Land zu verlassen. Schmidt bemühte sich einige Male um eine Verlängerung der Emigrationsfrist und um die Genehmigung, wenigstens teilweise im Land Eigentum zu behalten. Zur Persönlichkeit Stephan Schmidts von Freihofen Tomáš Knoz, Die mährische Emigration nach 1620, in: Rudolf Leeb/ Susanne C. Pils/Thomas Winkelbauer (Hg.), Staatsmacht und Seelenheil. Gegenreformation und Geheimprotestantismus in der Habsburgermonarchie (Veröffentlichungen des Instituts für Österreichische Geschichtsforschung 47), Wien/München 2007, S. $247-$ 262, hier S. 257-260.

16 Vgl. u. a. Josef VÁlKa, K otázkám úlohy Moravy v české reformaci [Zur Frage der Rolle Mährens in der böhmischen Reformation], in: Studia Comeniana et Historica 15 (1985), S. 67-80; Ders., Dějiny Moravy II (wie Anm. 6); Ders., Morava ve struktuře a historii českého lenního a stavovského státu. Nástin problematiky [Mähren in der Struktur und Geschichte des böhmischen Lehns- und Ständestaates], in: Antonín Verbík/Karel Blažek (Hg.), Moravský historický sborník, Brno 1986, S. 22-45; Ders., Společnost a kultura baroka na Moravě [Gesellschaft und Barockkultur in Mähren], in: Ivo Krsek/Zdeněk Kudělka/Miloš Stehlík/Josef Válka (Hg.), Umění baroka na Moravě a ve Slezsku, Praha 1996, S. 14-41; Ders., Morava, země v srdci střední Evropy [Mähren, ein Land im Herzen Europas], in: Jiří Kroupa (Hg.), V zrcadle stínů. Morava v době baroka, Brno/Rennes 2003, S. 15-35.

17 VÁclav Medek, Cesta české a moravské církve staletími [Der Weg der böhmischen und mährischen Kirche durch die Jahrhunderte], Praha 1982. Hier v. a. Kapitel 12: Katolická 
quantitativ nicht sehr bedeutsam und spielten auch im rechtlichen und politischen System des Landes lediglich eine begrenzte Rolle. ${ }^{18}$ Demgegenüber nahm in Mähren der Adel die entscheidende gesellschaftliche Rolle ein, und dies trotz der Tatsache, dass dessen aristokratische Bestandteile sich durch Tradition und rechtliche Normen von der Stellung der Magnatenfamilien in Polen bzw. Ungarn unterschieden, was sich darüber hinaus nur in begrenztem Umfang bei der Konstituierung der neuen Fürstenschicht zu Beginn des 17. Jahrhunderts veränderte. ${ }^{19}$

Die Integration des „landfremden Adels“ im Milieu der mährischen Gesellschaft erfolgte vornehmlich aus den Nachbarländern, die zudem in einigen Fällen die Integration des aus weiter entfernteren Gebieten stammenden Adels (Osterreich für Innerösterreich, Italien, das Reich, die Spanischen Niederlande, Böhmen für das Reich und die Gebiete Westeuropas, Schlesien für die Polnisch-Litauische Union, Oberungarn für Niederungarn) vermittelten. ${ }^{20}$ Ein gewisses Spezifikum bildete dabei die Integration aus Böhmen und Schlesien, wo nicht die Notwendigkeit der Erlangung eines Inkolats bestand. Die Integration gestaltete sich daher wesentlich leichter (was unter den spezifischen Bedingungen das politische Geschehen im Lande beeinflussen konnte, aber auch den kulturellen Transfer), und in Mähren entstanden häufig Enklaven von Besitzungen der in den Nachbarländern ansässigen Familien (u. a. die Thurn in

obnova na Moravě [Die katholische Erneuerung in Mähren] und 13: František kardinál Ditrichštejn [Franz Kardinal Dietrichstein], S. 183-191; Onď̌ej Jakubec (Hg.), Stanislav Pavlovský z Pavlovic (1579-1598). Biskup a mecenáš umírajícího věku [Stanislaus Pavlovsky von Pavlowitz (1579-1598). Bischof und Mäzen eines untergehenden Zeitalters], Olomouc 2009; Leoš MцČÁk (Hg.), Kardinál František z Dietrichsteina (1570-1636). Prelát a politik neklidného věku [Kardinal Franz von Dietrichstein (1570-1636). Prälat und Politiker eines unruhigen Zeitalters], Olomouc 2008.

18 FrantišEK KameníčeK, Zemské sněmy a sjezdy moravské [Die Landesversammlungen und mährischen Landtage], Bd. 3, Praha 1905, Kap. 8: Města královská, komorní a poddaná [Die königlichen, Kammer- und Untertanen-Städte], S. 102-117, sowie Kap. 9: Źivot v městech moravských [Das Leben in den mährischen Städten], S. 117-149; Jaroslav Marek, Městská sít na Moravě v 15. a 16. století. Studie o moravské společnosti v době jagellonské [Das städtische Netz in Mähren im 15. und 16. Jahrhundert. Eine Studie über die mährische Gesellschaft in der Jagiellonenzeit], in: Časopis Matice moravské 90 (1971), S. 281-303; DERs., Společenská struktura moravských královských měst v 15. a 16. století [Die gesellschaftliche Struktur der mährischen Städte im 15. und 16. Jahrhundert], Praha 1965.

19 Tomáš Knoz, Moravská barokní šlechta [Der mährische Barockadel], in: Ders. (Hg.), Morava v době baroka, Brno 2004, S. 45-54. Zur Konstituierung der neuen Fürstenschicht in den böhmischen Ländern allgemein MAŤA, Svět české aristokracie (wie Anm. 2), S. 69-74.

20 So wurden beispielsweise zahlreiche ihrer Herkunft nach polnische Adelige zuerst in Schlesien integriert, etwa im polnischsprachigen Adel, und am Ende geschah dies - ohne die Pflicht des Inkolats - auch innerhalb der mährischen Adelsgesellschaft. Als in Olmütz Stanislaus Pavlovský sein Bischofsamt ausübte, wurde innerhalb des mährischen Adels eine Diskussion darüber geführt, ob man in dem Metropoliten einen Polen oder einen Schlesier sehen solle. Vgl. KNOz, Integration des Adels schlesischer Herkunft (wie Anm. 1), S. 263-292. Ähnlich war dies der Fall auch in Österreich, wo sich die Angehörigen aus den weiter entfernteren österreichischen Ländern (z. B. die Freihofen bzw. Verdenberg aus der Steiermark) oder schließlich sogar aus dem Reich (Kaltschmidt von Eisenberg aus Ingolstadt) etablierten, die am Ende Besitz in Mähren erwarben und hier mehr oder minder als Angehörige des österreichischen bzw. des Wiener Hofadels galten. 


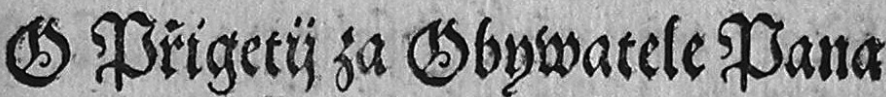
LEmryda Docýbo.

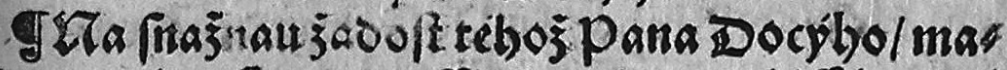
güce o geho Cenem a fllechetnem (zwläfite proti

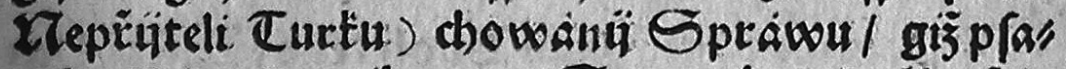
nébo pána Docybo/ y a Syny gebo od nébo ría. oné зplozenýmil za Obywatele toboto arargs

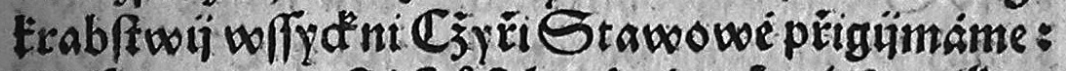

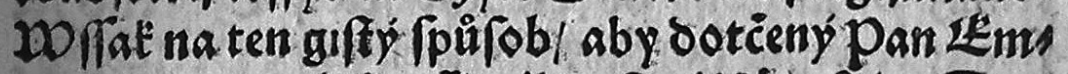
eych Docý/rate wo Zirálowftwi. Dherftém Stas wu $D$ รั่ iy Zlureonúty / a pany Saudoy zemftymi / pez: neypew prüfifin Saudu zemferm/fterys wo toms to hlarglicab/fwä oržcin bude/ to otiazal a Lift Lanoffiryou poolé por̈ablu zemé této / theywys" fímu panu püfači tracgetrab/faú toboto/s njm: [e to poole Ruffitoficonowagic/oal a oowed.

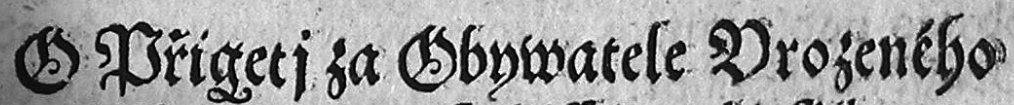
Dolaoyty pana Lutáfe Dembiaftého.

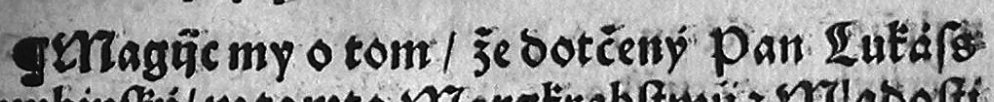

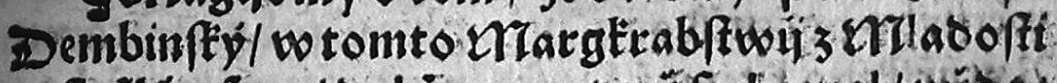

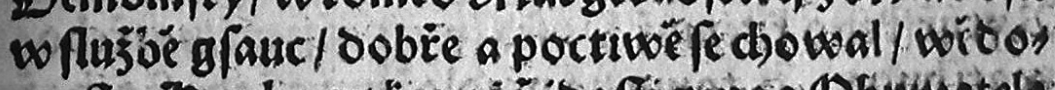

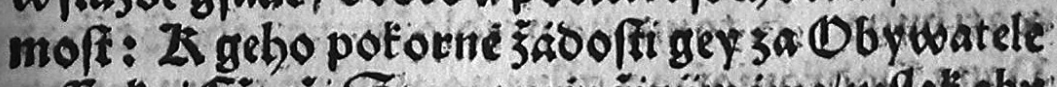

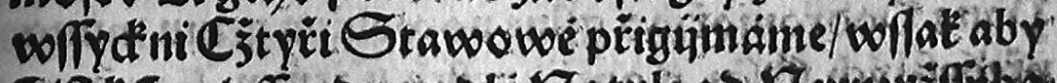

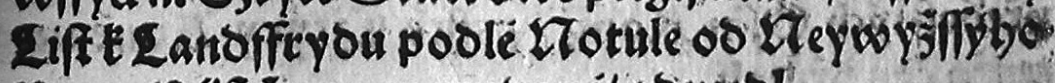
Pana pífar̃e gemu wyoanél os wede ol.
谜 iii.
ortas 
Wostitz/Vlasatice und Groß Niemtschitz/Velké Něměice), ${ }^{21}$ was als Element für die zumindest theoretisch sich festigende Einheit der Gruppe der Länder der St.-WenzelsKrone angesehen werden kann. ${ }^{22}$

Einen weiteren Typ der Integration aus den Nachbarländern stellt die Herausbildung regelrechter Besitzinseln einer Familie bzw. letztlich einer einzigen Person dar, die die Landesgrenzen überschritten. Als natürlich erwies sich dies wiederum im Falle des Königreichs Böhmen. Im Falle der Pernsteiner geht es dennoch eher um eine Integration in umgekehrter Richtung, während sich mit Blick auf die Integration in Mähren aus dem Milieu der böhmischen Aristokratie das Beispiel der Herren von Neuhaus als exemplarisch bezeichnen lässt. ${ }^{23}$ Im Falle Schlesiens finden sich wiederum zahlreiche Adelsgeschlechter, die mit ihren Familienbesitzungen die schlesisch-mährische Grenze überlagerten (sehr häufig im Gebiet von Ratibor), eine eigenständige Rolle spielte wiederum die Lage des Fürstentums Troppau (Opava), das bis in die erste Hälfte des 17. Jahrhunderts noch nicht als schlesisches Fürstentum angesehen wurde. Nach Ostmähren drängte der Veränderung wegen der Adel aus Oberungarn (diesen Prozess hat Zdeněk Pokluda detailliert beschrieben), sodass territoriale Einheiten wie Holitsch-Göding/Holič-Hodonín in den Händen der Familie Pálffy von Erdöd entstanden.

Im Falle des ungarischen Adels in Ostmähren gilt darüber hinaus, dass es sich in der Zeit vor der Schlacht am Weißen Berg sehr häufig um Lutheraner handelte, die bis auf Ausnahmen bereitwillig gegenüber der Konversion mit dem Beginn der Gegenreformation aus Mähren zurückwichen (Illésházy) und nach einer gewissen Zeit entweder nach der Konvertierung zurückkehrten oder aber durch Angehörige katholischer Familien ersetzt wurden (Pázmány, Sérényi). ${ }^{24}$ Im Falle der österreichischen Grenze kam es bereits seit dem Mittelalter zu deren Überschreitung, dieser Prozess intensivierte sich zudem nach der Thronbesteigung der österreichischen Habsburger in Böhmen bzw. dem Übergang der Markgrafenwürde in Mähren an diese. Mit einer gewissen Übertreibung können wir von einem „liechtensteinischen Modell“ sprechen, das vor der Schlacht am Weißen Berg u. a. die Familien Althann, Teufenbach, Teufl, Strein von Schwarzenau und nach 1621 z. B. die Breuner oder die Herren von Meggau applizierten. ${ }^{25}$ Sämtliche oben erwähnten Modelle der Integration aus den Nachbar-

21 Františex Hrubý, Hrabata z Thurnu a Valsassina. Dějiny jejich českomoravské větve [Die Grafen Thurn und Valsassina. Geschichte ihres mährischen Zweiges], in: Český časopis historický 28 (1922), S. 74-108, 305-334; Ders., Moravská šlechta roku 1619, její jmění a náboženské vyznání [Der mährische Adel des Jahres 1619, seine Güter und sein konfessionelles Bekennnis], in: Časopis Matice moravské 46 (1922), S. 107-169.

22 Josef VÁlKa, Čechy a Morava ve stavovských povstáních [Böhmen und Mähren in den Ständeaufständen], in: Sborník prací filosofické fakulty brn nské university C/34 (1987), S. 119-129; Ders., Morava ve struktuře (wie Anm. 16), S. 22-45.

23 Petr Vorel (Hg.), Pernštejnové v českých dějinách [Die Herren von Pernstein in der tschechischen Geschichte], in: Sborník příspěvků z konference v Pardubicích 8.-9. 9. 1993, Pardubice 1995, S. 105-114; VÁclav Ledvinka, Rezidenční města pánů z Hradce v 16. a na počátku 17. století [Die Residenzstädte der Herren von Neuhaus im 16. und zu Beginn des 17. Jahrhunderts], in: Michaela Kokojanová (Hg.), Měšlané, šlechta a duchovenstvo v rezidenčních městech raného novověku, Prostějov 1997, S. 119-154; BƯžEK (Hg.), Poslední páni z Hradce [Die letzten Herren von Neuhaus] (Opera historica 6), České Budějovice 1998.

24 Pokluda, Majetek uherské šlechty (wie Anm. 1), S. 296-325.

25 Thomas Winkelbauer, Die Liechtenstein als "grenzüberschreitendes Adelsgeschlecht“. Eine Skizze der Entwicklung des Besitzes der Herren und Fürsten von Liechtenstein in Niederösterreich und Mähren im Rahmen der politischen Geschichte, in: Andrea 
ländern beschränkten sich darüber hinaus ausschließlich auf die aristokratischen Eliten, denn sie umfassten das gesamte Spektrum des frühneuzeitlichen Adels (ein Teil der Angehörigen des „landfremden Adels“ folgte seinen Verwandten, ein Teil als deren Höflinge und Beamte), sodass die Integration in hohem Maße einen komplexen Charakter besaß.

\section{Rechtsnorm}

Die grundlegende Rechtsnorm, die in der Frühen Neuzeit das Prinzip der Integration zum Ausdruck brachte, ist die des Inkolats. ${ }^{26}$ Diese Rechtsnorm bildete auf allgemeinlegislativer Ebene einen Bestandteil der Landesinstitutionen - im Falle Mährens der mährischen Landeseinrichtungen. ${ }^{27}$ Individuell wurde sie auf den Verhandlungen der

Komlosy/Václav Bůžek/František Svátek (Hg.), Kulturen an der Grenze. Waldviertel - Weinviertel - Südböhmen - Südmähren, Wien 1995, S. 219-226; Ders., Wandlungen des mährischen Adels um 1600, in: Karlheinz Mack (Hg.), Jan Amos Comenius und die Politik seiner Zeit, Wien/München 1992, S. 16-36.

26 Anton Gindely, Die Entwicklung des böhmischen Adels und der Inkolatsverhältnisse seit dem 16. Jahrhunderte, Prag 1886; August von Doerr, Verzeichnis der InkolatsErtheilungen und Aufnahmen in den Herrenstand in Mähren aus der Jahren 1531-1620, Prag 1903 (hier und ähnlich auch bei Kameníček ein Verzeichnis der erteilten Inkolate vor der Schlacht am Weißen Berg); Vladimír Klecanda, Přijímání cizozemců na sněmu do Čech za obyvatele. Př́íspěvek k dějinám inkolátu před Obnoveným zřízením zemským [Die Aufnahme von Landfremden als Bürger in Böhmen auf dem Landtag. Ein Beitrag zur Geschichte des Inkolats vor der Erneuerten Landesordnung], in: Sborník prací věnovaných prof. Gustavu Friedrichovi, Praha 1931, S. 456-467. In jüngster Zeit haben sich mit der Problematik der rechtlichen Zusammenhänge mit Blick auf das Inkolat vornehmlich Jana und Dalibor Janiš befasst. Jana Janišová/Dalibor JANiš, Postavení cizinců a inkolát podle moravského zemského práva v 16. a na počátku 17. století [Die Stellung der Landfremden und das Inkolat nach dem mährischen Landrecht im 16. und zu Beginn des 17. Jahrhunderts], in: Miroslav Svoboda (Hg.), Morava jako zrcadlo Evropy. Etnické menšiny na Moravě a do roku 1918 (Mikulovská sympozia 31), Brno 2010, S. 191-201. Hier muss freilich angemerkt werden, dass die Autoren den Terminus "Landfremder" (cizinec) vornehmlich auf der Grundlage formalrechtlicher Kriterien definieren, was nicht immer ganz der allgemeinen zeitlichen Wahrnehmung des Problems entspricht.

27 Mit der Frage der Landesordnungen in Mähren hat sich František Č́a gründlich befasst, der zudem als erster Historiker den Text der Landesordnung von 1535 edierte, die darüber hinaus einen Vergleich mit dem Text aus dem Jahre 1562 enthält. FrantišEK Č́́DA (Hg.), Zemské zřízení moravské z r. 1535 spolu s tiskem z r. 1562 nově vydaným [Die mährische Landesordnung aus dem Jahre 1535 gemeinsam mit dem Druck von 1562 neu herausgegeben], Praha 1937. Eine Analyse der Landesordnungen findet sich darüber hinaus in dem bereits zitierten Werk von František Kameníček. Gegenwärtig befassen sich mit den Landesordnungen Jana und Dalibor Janiš. Vgl. Dalibor Janiš, Práva a zřízení Markrabství moravského z roku 1545. Pokus moravských stavů o revizi zemského zrrízení. Historický úvod a edice [Die Rechte und Ordnungen der Markgrafschaft Mähren aus dem Jahre 1545. Der Versuch der mährischen Stände hinsichtlich einer Revision der Landesordnung. Historische Einleitung und Edition] (Prameny dějin moravských 9), Brno 2005; Jana Janišová/Dalibor Janiš, Zemské zrrízení Markrabství moravského z roku 1516 [Landesordnung der Markgrafschaft Mähren aus dem Jahre 1516], Olomouc 2013; Jana JanišovÁ, Zrízení zemské Markrabství moravského z roku 1604 [Landesordnung der Markgrafschaft Mähren aus dem Jahre 
Landtage mit Leben erfüllt; als individueller Rechtsakt der Verallgemeinerung im legislativen Prinzip wurde sodann der Beschluss des Landtages über die Erteilung des Inkolats als Rechtsnorm (bzw. ihre Applikation) im Rahmen der „Gemeinde-Artikel“ im Memorialbuch des Landtags eingetragen bzw. später in gedruckter Form im entsprechenden Jahrgang der Landtagsmitteilungen.

In diesem Zusammenhang muss jedoch betont werden, dass die Regeln des Inkolats eher den rechtlich-formalen Aspekt der Integration zum Ausdruck brachten und nicht dessen Tiefe bzw. innere Bedeutung verdeutlichten. Dennoch lassen sich einige interessante Aspekte der Integration auch aus deren rechtlichem Rahmen ablesen. Wenn wir die Möglichkeit der statistischen Auswertung der Bitten um Erteilung des Inkolats aus verschiedenen geografischen, sozialen, konfessionellen und familiären Milieus bzw. statistische und analytische Wertungen der Akzeptanz bzw. Ablehnung der Bitten um Inkolat vonseiten der Landtage einmal außer Acht lassen, ${ }^{28}$ rezipieren auch die Normen des Inkolats das Verhältnis der Markgrafschaft Mähren zu den übrigen Ländern: Die aus den Ländern der St.-Wenzels-Krone stammenden Adeligen wurden nämlich durch das mährische Verfassungsrecht als einheimische Aristokraten betrachtet und mussten keineswegs um die Erteilung eines besonderen Inkolats bitten. Diese Tatsache besaß nicht allein formalrechtliche, sondern auch politische Aspekte, sodass zum Beispiel im Zeitraum um 1600 nach Mähren eine ganze Gruppe von Angehörigen des katholischen Adels aus Böhmen kommen konnte, um im Land die politisch-konfessionelle Struktur zu verändern. ${ }^{29}$ Andererseits vermochten in der Krisenzeit um das Jahr 1618 radikale böhmische Protestanten ins Land zu gelangen und hier letztlich politische und militärische Funktionen zu bekleiden. ${ }^{30}$

1604, Praha 2015; Jana Janišová/Dalibor Janiš, Moravská zemská zřízení a kodifikace zemského práva ve střední Evropě v 16. a na počátku 17. století [Mährische Landesordnungen und die Kodifikationen des Landrechts in Mitteleuropa im 16. und am Anfang des 17. Jahrhunderts], Praha 2016.

28 Moravský zemský archiv, Stavovské rukopisy, A 3, Památky sněmovní, Nr. 4-7 [Mährisches Landesarchiv, Stände-Handschriften, A 3, Bestand der Stände, Nr. 4-7]; Moravský zemský archiv, Sněmovní tisky, A 6, Sněmovní usnesení z let 1590-1612 [Stände-Drucke, Ständebeschlüsse aus den Jahren 1590-1612].

29 So trat beispielsweise Ladislav Berka von Duba als Führungspersönlichkeit einer Gruppe jüngerer Aristokraten auf, die in Mähren die Interessen Kaiser Rudolfs II. repräsentieren sollte und auf ihre Art und Weise damit auch die Interessen der katholischen Gegenreformation. Im Falle Ladislav Berkas wird aufgrund der in den Beständen der böhmischen Hofkanzlei erhaltenen Quellen gut sichtbar, dass besagter Adeliger nach Mähren entsandt wurde um in eines der einflussreichen Landesämter zu gelangen und somit im Lande die Politik Kaiser Rudolfs II. durchzusetzen. Der Kaiser ließ sich zunächst von den mährischen Landesrichtern begründen, warum es so lange dauere, bis Berka das Amt des Oberstkämmerers bekleiden könne. Schließlich erhielt er eine ähnliche Begründung mit beigefügter Entschuldigung auch von Berka selbst. Národní archiv Praha, fond Morava - Moravské spisy české kanceláře a české komory, Nr. 4157 [Nationalarchiv Prag, Fonds Mähren - Mährische Akten der böhmischen Kanzlei und der böhmischen Kammer, Nr. 4157], Ladislav Berka von Duba entschuldigt sich beim Kaiser, dass er bislang keinerlei Funktion bekleide, da keines der Ämter (Oberstkämmerer und Landeshauptmann) ihm bislang angetragen worden sei-1598, August 20, fol. 2.

30 FrantišEk MatĚjek, Morava za třicetileté války [Mähren im Dreißigjährigen Krieg], Praha 1992, S. 1-28; Miloš Pojar, Jindřich Matyáš z Thurnu. Muž činum [Heinrich Matthias von Thurn. Ein Mann der Taten], Praha 1999. 
Ähnlich spiegelte sich die Norm des Inkolats auch im verfassungspolitischen Prinzip der Amtssprache als integrierendes Element des Landes wider. Es handelte sich um eine Norm, die in einem äquivalenten Verhältnis zum Grundbesitz stand: Das Inkolat war die Voraussetzung zur Gewinnung bzw. zumindest die Bestätigung des zu erwartenden Erwerbs von Grundbesitz - und umgekehrt verfiel bei Nichterwerb von Grundbesitz im Lande nach Annahme als Bürger das Inkolatsrecht. ${ }^{31}$ Dessen ungeachtet verhielt sie sich implikativ zur Landessprache, es wurde nicht davon ausgegangen, dass der ein Inkolat erwerbende Adelige notwendigerweise die Landessprache - also Tschechisch - erlernen musste, dennoch war dies eine Bedingung sine qua non mit Blick auf eine vollständige Integration und die Möglichkeiten des Bewerbers um ein Inkolat sich an der politischen und verfassungsmäßigen Entwicklung des Landes zu beteiligen. ${ }^{32}$ Diese Aspekte veränderten sich dennoch nach Herausgabe der Erneuerten Landesordnung bzw. nach der rechtlichen Emanzipation des Deutschen und Tschechischen als der beiden gleichberechtigten amtlichen Landessprachen.

31 František Kameníček konstatiert am Ende seiner Beschreibung der umfangreichen Freiheiten, rechtlichen Regularien und zeitgenössischen außerrechtlichen Prinzipien bei der Erteilung der Inkolate und der Aufnahme von Landfremden mit dem Inkolat im Lande lapidar, dass „die Erneuerte Landesordnung auch diesem bedeutenden ständischen Privileg dadurch ein Ende bereitete, dass das Inkolat vollständig der Herrschergewalt oblag". Diese Charakteristik gilt im Grunde genommen bis heute, und zwar trotz der Tatsache, dass die gegenwärtige Rechtsgeschichte eine wesentlich genauere Definition des Inkolatsrechts in Mähren nach der Schlacht am Weißen Berg vornahm, und zwar im zeitgeschichtlichen Kontext. KameníčeK, Zemské sněmy (wie Anm. 18), Bd. 3, S. 94. Zum Wegfall des Inkolats bei Nichterwerb von Besitz im Lande vgl. den entsprechenden Artikel: Über im Lande aufgenommene Ausländer. Da in den nunmebr zurückliegenden Jabren eine nicht geringe Zabl von Personen landfremder Herkunft als Bewohner der Markgrafschaft Mäbren Aufnabme gefunden hat, die bisher weder bier im Lande, im Königreich Böbmen noch in anderen, diesem zugebörigen Ländern keinerlei Güter als Erbe, in Pfandschaft oder in irgendeiner anderen Form besitzen, haben daraufhin alle vier Stände (bierfür zablreiche gute Gründe vorführend) beschlossen, dass, sollten diese Personen von uns somit mit Abschluss dieses Landtags als Bewohner aufgenommen werden, innerhalb von drei Jabren fortan keinerlei derartige Güter wie besagt erwerben, und zwar im Königreich Böbmen, in der Mark [grafschaft] Mäbren sowie in anderen, zu diesem Königreich gehörenden Ländern, dann sollen sie aus den Landesregistern vom obersten Schreiber gestrichen und nicht mehr als Bewohner gefübrt werden. Und diejenigen, die danach als Bewohner aufgenommen werden, sollen sich ebenso verbalten. Moravský zemský archiv Brno, Památky sněmovní, A 3, Nr. 3, fol. 320r - nové foliování [Mährisches Landesarchiv Brünn, Denkwürdigkeiten der Stände, A 3, Nr. 3, fol. 320r - neue Foliierung].

32 Der Fall Kardinal Franz von Dietrichsteins ist hinreichend bekannt, zuletzt zu seiner Integration in der mährischen Politik PAVEl BALcÁrek, Kardinál František Ditrichštejn 1570-1636. Gubernátor Moravy [Kardinal Franz Dietrichstein 1570-1636. Gubernator Mährens], České Budějovice 2007. Hier auch Hinweise auf die umfangreiche Literatur zur politischen Karriere des Dietrichsteiners in Mähren und in der Habsburgermonarchie. Demgegenüber erfüllte Heinrich Matthias Thurn lediglich die Bedingung des Besitzerwerbs in Böhmen, ungeachtet dessen erlernte er das Tschechische als politische Amtssprache im Lande seinen Biografen zufolge nie richtig. Vgl. Ders., Ve víru trricetileté války. Politikové, kondotiéri, rebelové a mučedníci v Zemích koruny české [Für den Glauben im Dreißigjährigen Krieg. Politiker, Condottieri, Rebellen und Märtyrer in den Ländern der Böhmischen Krone], České Budějovice 2011, S. 189-251, hier v. a. S. 195. 
In ähnlicher Weise spiegelte die Normativität des Inkolats auch den Prozess der Veränderung der Verfassungsprinzipien des Landes wider, den wir vereinfachend als Prozess der Entwicklung vom ständischen System zum Absolutismus bezeichnen wollen. ${ }^{33}$ Vor der Schlacht am Weißen Berg (noch auf der Grundlage der mährischen Ständeordnung aus dem Jahre 1604) lagen die Erteilung des Inkolats und auch die Konfirmation der besitzrechtlichen Gewinne im Lande in der Kompetenz der Stände und des Landtags. ${ }^{34}$ Nach 1621 (auf der Grundlage der Erneuerten Landesordnung aus dem Jahre 1628) erfolgten die Eintragungen in die Landtagsbeschlüsse und die Landtafeln lediglich mit expliziter Zustimmung des Herrschers/Landesherrn. ${ }^{35}$

Selbstverständlich ist, dass die Frage der Rechtsnorm als einer Art bestimmendes Element der Integration des Adels in der mährischen Adelsgesellschaft durch die Erteilung des Inkolats keineswegs gelöst war. Eine wichtige Frage stellte nämlich auch die Akzeptanz der mährischen Rechtssysteme vonseiten des neu ins Land kommenden Adels dar, und dies nicht allein auf der Ebene des Landrechts, sondern auch jener des obrigkeitlichen Rechts. Einige der ankommenden Adeligen brachten aus ihren Ländern eigene Rechtsgewohnheiten mit und versuchten diese als grundbesitzende Obrigkeiten auf ihre neue Umgebung zu applizieren, etwa in der Frage der Gerichtshoheit. Im Milieu des mährischen Rechts, in dem zahlreiche seiner Repräsentanten die Position des rechtlichen Legalismus vertraten und das Landesrecht für sie die oberste Autorität darstellte (womöglich mitunter eine größere Autorität als jene des Landesherrn), konnte eine unzureichende Akzeptanz des mährischen Rechtssystems durch

33 Selbstverständlich im Wissen um die Kompliziertheit der Debatte, die um dieses Thema in den Neunzigerjahren des 20. sowie zu Beginn des 21. Jahrhunderts geführt wurde und die zahlreiche Aspekte des erwähnten Prozesses - einschließlich der historiografischen Terminologie - zu klären vermochte. Aus der umfangreichen Literatur diesbezüglich vgl. v. a. Nicholas Henshall, The Myth of Absolutism. Change and Continuity in Early Modern European Monarchy, London/New York 1992; WINFRIED Schmale, Absolutismus: Biographie eines Begriffs, in: Beiträge zur historischen Sozialkunde 4 (2001), S. 5-13; ERnst Hinrichs, Abschied vom Absolutismus? Eine Antwort auf Nicholas Henshall, in: Ronald G. Asch/Heinz Duchhardt (Hg.), Absolutismus - ein Mythos? Strukturwandel monarchischer Herrschaft in West- und Mitteleuropa (ca. 1550-1700) (Münstersche Historische Forschungen 9), Köln/Weimar/Wien 1996, S. 353-371; Rudolf Vierhaus, Barock und Absolutismus, in: Klaus Garber (Hg.), Europäische Barock-Rezeption (Wolfenbütteler Arbeiten zur Barockforschung 20), Wiesbaden 1991, S. 45-61; Heinz Duchhardt, Absolutismus - Abschied von einem Epochenbegriff?, in: Historische Zeitschrift 258 (1994), S. 113-122; ERnst Hinrichs, Fürsten und Mächte. Zum Problem des europäischen Absolutismus, Göttingen 2000.

34 In der Landesordnung aus dem Jahre 1535 lautet der entsprechende Artikel wie folgt: 148. Über das Einkaufen der Landfremden in das Land. Gleichwie dies die vorangegangene Ordnung bestimmt hat, soll, wenn irgendein Landfremder ein Gut in dieser Markgrafschaft zu kaufen beabsichtigt, er dies vor den Ständen dieser Markgrafschaft, die ibn zum Bewohner annehmen wollen, vortragen. Und wenn es vorkommt, dass die Einwohner und Landfremden bereits irdische Güter verkaufen und Verträge schließen, noch ehe die Landfremden von den Ständen aufgenommen werden. Daher soll derjenige, der dies zulässt und zuerst mit dem Landfremden über das Gut verhandelt und es ihm verkauft, noch ehe ersterer Aufnabme gefunden hat, von den Ständen bestraft werden, zusammen mit jenen, die einen solchen Vertrag konfirmiert haben. FRANTIŠEK ČÁDA (Hg.), Zemské zřízení moravské z r. 1535 spolu s tiskem z r. 1562 nově vydaným [Die mährische Landesordnung aus dem Jahre 1535 gemeinsam mit dem Druck von 1562, neu herausgegeben] (Historický archiv 50), Praha 1937, S. 202.

Knoz, Pobělohorské konfiskace (wie Anm. 3), S. 287-292. 
den neu ankommenden Adeligen ein Hindernis für seine Integration in die mährische Adelsgesellschaft darstellen. Mit gewissen Einschränkungen wurden so in Mähren in der Frühen Neuzeit im Verlaufe des 16. Jahrhunderts im allgemeinen Bewusstsein einige landfremde aristokratische Titel übernommen, noch langsamer freilich wurde ihnen auch eine konkrete rechtliche Validität zuerkannt. Ähnlich gestaltete sich die Situation im Bereich des obrigkeitlichen Rechts, wo in der Ära vor der Schlacht am Weißen Berg einige Spezifika der rechtlichen Stellung der Untertanen gegenüber der Obrigkeit und gegenüber dem Landesrecht zum Ausdruck kamen.

Vermutlich bezeugt diese Problematik am besten die bekannte Korrespondenz vom Ende des 16. und beginnenden 17. Jahrhunderts zwischen Karl d. Ä. von Žerotín (zu dieser Zeit mährischer Landesrichter) und dem ungarischen Adeligen, dem Palatin Stefan Illésházy, der in Mähren die Herrschaft Tobitschau (Tovačov) erwarb. Diesen ermahnte Žerotín streng, dass er seinen Untertanen gegenüber eine gewisse Ehrfurcht und Milde walten lassen solle. In der Serie der Briefe aus dem Jahre 1598 wies Žerotín Illésházy darauf hin, er möge auch in seinen Beziehungen zu den Untertanen in Mähren die hiesigen Gesetze und Gewohnheiten respektieren, die sich in vielerlei Hinsicht von den Verhältnissen in seiner ursprüngliche Heimat unterschieden. Den Tobitschauer Untertanen sollten Žerotín zufolge keine neuen Lasten und Hürden auferlegt werden, die den Umfang der Arbeiten, wie sie in den hiesigen Urbarien verzeichnet seien, überschritten, und es sollten auf diese Art und Weise nicht zu deren Lasten die Einnahmen der Obrigkeit erhöht werden. Darüber hinaus machte Žerotín Illésházy auch auf die Tatsache aufmerksam, dass in derartigen Fällen das mährische Landesrecht erlaube, dass die Untertanen vor der eigenen Obrigkeit Schutz beim Landeshauptmann sowie weiteren mährischen Ständebeamten suchten. Dies könnte Žerotín zufolge zu einem Ansehensverlust Illésházys führen, und zwar sowohl in den Augen seiner Untertanen als auch der übrigen mährischen Adeligen - und dies könne folglich ein Hindernis für seine Integration in Mähren darstellen. ${ }^{36}$

Beim sorgfältigen Lesen der Rechtstexte, die auf den Seiten der Denkwürdigkeiten der Landtage enthalten sind und die die Erteilung des Inkolats in Mähren auf allgemeiner (Artikel-Typ Über das Einkaufen der Landfremden in das Land) ${ }^{37}$ sowie auf individueller Ebene (Artikel-Typ Über die Annabme als Bürger des Herrn Gabriel Majlad" 38 regeln, lassen sich neben dem normativen Charakter der Artikel auch viel-

36 Tomáš Knoz, Karel starší ze Žerotína. Don Quijote v labyrintu světa (Velké postavy českých dějin 11) [Karl d. Ä. von Žerotín. Ein Don Quijote im Labyrinth der Welt (Große Gestalten der tschechischen Geschichte 11)], Praha 2008, S. 129-133.

37 Moravský zemský archiv Brno, Památky sněmovní, A 3, sv. 2 /2 II, fol. 197r - nové foliování [Mährisches Landesarchiv Brünn, Denkwürdigkeiten der Landtage, A 3, Bd. 2 /2 II, fol. $197^{r}$ - neue Foliierung]; der Wortlaut entspricht der oben in Anm. 34 zitierten Quelle.

38 Über die Aufnahme des Herrn Gabriel Majlad zum Bewohner. Auf ebendiesem Landtag in Znaim wurde auf die persönliche Bitte und Fürsprache des allergnädigsten und unbesiegbaren Fürsten und Herrn, Herrn Maximilian II., römischer Kaiser, König von Ungarn und Böbmen etc., Markgraf von Mäbren etc., unseres allergnädigsten Herrn, den seine kaiserliche Gnaden über alle vier Stände der Markgrafschaft Mäbren zu setzen beliebt hat, beschlossen, dass diese Herrn Gabriel Majlad Graf Fogaravsky als Bewohner in diese Markgrafschaft unter sich aufnehmen mögen. Auch auf die inständige Bitte dieses Herrn [wurde] Gabriel als gut und löblich sein Verbalten [anerkannt]. Diesen genannten Herrn Gabriel Majlad Graf Fogaravsky haben diese Stände auch mit den ordentlichen Wappen des Herrn aus gutem und freiem Willen als Bewohner in diese Markgrafschaft Mäbren an- und aufzunebmen beschlossen. Jedoch zuerst auf jene Weise, dass, sollte er irgendein Gut zu erwerben beabsichtigen, er dem Herrn [Landes-] 
schichtige zeremonielle und symbolische Akte im Handeln der mährischen Stände herauslesen, die sich durch die gesamte Inkolatsregelung ziehen. Vor allem die Bitte des Interessenten für eine Aufnahme im Land musste auf zeremonielle Art und Weise wie eine erniedrigende und flehentliche Bitte vorgetragen werden. Mitunter finden sich Vermerke darüber, dass, noch bevor der Bittsteller vor die auf dem Landtag versammelten Stände trat, er diese Bitte in ähnlicher Form auf inoffiziellem Boden, etwa in einem Wirtshaus, vortrug, wo die sich auf dem Landtag versammelnden Adeligen trafen und wohnten. Eine derartige nichtformale Zeremonie wurde selbstverständlich von blumigen Ansprachen begleitet und aller Wahrscheinlichkeit nach auch von gebührenden Trinksprüchen.

Einen weiteren symbolischen Bestandteil der Inkolatsregelung stellte der Gewinn einer ausreichenden Zahl an Fürsprechern dar, auf deren Meinung sich der Bittsteller berufen konnte. Diese Fürsprecher rekrutierten sich auf der einen Seite aus höfischen und Regierungskreisen (häufig der Herrscher, Vertreter seiner Familie und der Dynastie, hochgestellte Prälaten einschließlich Kardinal Dietrichsteins als oberster PrälatFürst im Lande). Auf der anderen Seite allerdings suchten sich die Interessenten an einem Inkolat als Fürsprecher auch einflussreiche Personen aus, die die eigentlichen Landstände repräsentierten. Selbstverständlich ist, dass weder die zugehörige Aufzählung aller Titel des Petenten sowie die Betonung seiner Verdienste um das Herrscherhaus und, soweit möglich, auch um das Land seines zukünftigen Wirkens, einschließlich der Deklaration des bisherigen und künftigen guten und löblichen Verbaltens fehlten, in einigen Fällen auch über die Grenzen Mährens hinweg auf der Grundlage des guten Rufes überprüft. Eine rechtliche und zugleich auch symbolische Form der Huldigung gegenüber diesem Land bildete die unbedingte Pflicht des Bittstellers, einen erforderlichen Eid als ritualisierte Form des Rechtsakts abzulegen und sich persönlich an den obersten Landesschreiber zu wenden, in dessen Hände ein sich zum Landfrieden bekennender Brief gelegt werden musste, in dem sich der Bittsteller zur Erfüllung aller Pflichten und zum Respekt gegenüber dem mährischen Landesrecht, allen Landesgewohnheiten und Bräuchen verpflichtete. ${ }^{39}$

Hauptmann einen Brief, in dem er sich zum Landfrieden bekenne, übergebe und er sich gemäß der Ordnung dieser Markgrafschaft zu verhalten verpflichte. Moravský zemský archiv Brno, Památky sněmovní, A 3, sv. 2 /2 II, fol. 291 ${ }^{\mathrm{r}}-291^{\mathrm{v}}$ - nové foliování [Mährisches Landesarchiv Brünn, Denkwürdigkeiten der Landtage, A 3, Bd. 2 /2 II, fol. $291^{\mathrm{r}}-291^{\mathrm{v}}$ - neue Foliierung].

39 Die Bedingung des guten Verbaltens und der Zuneigung zum Lande kommt im Fall des Inkolats für den ungarischen Adeligen Pavel Czobor deutlich zum Vorschein. In dem sich mit seiner Person befassenden Artikel tauchen zudem weitere symbolische Bedingungen für die Erteilung des Inkolats, die im Text Erwähnung finden, auf: Über die Aufnabme zum Bewohner des woblgeboren Herrn Pavel Czobor von Czobor und von Sankt Michael und auf Stráž, Seiner Gnaden des römischen Kaisers, des ungarischen und böhmischen Königs etc. Rat, und der woblgeboren Wladyken Herrn Ludwig Tochynský von Tochynè, Herrn Stefan Ledenský von Ledenice. Wir, die vier Stände, sind übereingekommen, dass sich Herr Pavel Czobor, der im Königreich Ungarn an der Grenze zur Markgrafschaft Mäbren ansässig ist, uns wobl bekannt ist und dass er sich uns gegenüber, den Ständen dieser Markgrafschaft, stets freundschaftlich und nachbarschaftlich verbalten hat und verbält, und besonders den Ständen dieser Markgrafschaft zugeneigt ist. Auch schätzen wir die liebenswürdige Fürsprache I[brer] K[aiserlichen] G[naden], unseres gnädigsten Herrn, sowie Ibrer Gnaden, des Erzherzogs Ernst, Herzog von Österreich, für die woblgeborenen Wladyken, die Herren Ludwig Tochynský und Stefan Ledenský bestimmt, den oben genannten Herrn Pavel Czobor auf seine Bitte hin sowie die Herren Ludwig Tochynský und Stefan Ledenský als 


\section{Symbolische Form}

Die rechtliche Ebene der Integration des „landfremden Adels“ in Mähren in der Frühen Neuzeit war für gewöhnlich häufig implikativ mit der symbolischen Ebene verknüpft. Der Autor des vorliegenden Beitrags hat versucht, auf dieses Phänomen vor einiger Zeit bei der Analyse der genealogischen und symbolischen Zusammenhänge im Ahnen-Saal der Familie Althann auf Schloss Frain (Vranov nad Dyji) in Südmähren hinzuweisen. Die hier verwendeten Symbole lassen sich für genealogische Forschungen heranziehen, zumal diese Symbole auf die Erlangung einer höheren rechtlichen und sozialen Position der Familie verweisen. Text- und Bildmittel aus dem Ahnen-Saal untermauerten folglich symbolisch diesen Aufstieg. ${ }^{40}$ Die symbolische Form der Integration umfasste häufig die gesamte Skala der Text- und Bildmittel, die miteinander kommunizierten. Im Falle der Texte handelte es sich um rein rechtliche (normative und nichtnormative), genealogische, narrative, emblematische Texte, im Falle der bildkünstlerischen Mittel ging es um ikonografische und ikonologische Werke, um Emblematik und Heraldik, um malerische, zeichnerische und grafische Formen, um bildhauerische und architektonische Kompositionen, in der Regel in den unterschiedlichsten Formen gegenseitiger Interaktion. Die erwähnten symbolischen Formen im Zeitraum der Frühen Neuzeit ermöglichten es darüber hinaus, den symbolischen formalrechtlichen Rahmen der Integration in Richtung einer tieferen Hervorhebung des Verhältnisses zum Land zu überschreiten, und dies wiederum auf der Achse zwischen Erfüllung allgemeiner Erwartung, individueller Familientradition und konkreter Absicht und Ziel der Anwendung im Rahmen der Adelsgesellschaft im Lande. ${ }^{41}$

Wie die Texte der von Bartholomäus Paprocký an der Wende vom 16. zum 17. Jahrhundert herausgegebenen Texte heraldischer Legenden relativ gut aufzeigen (vor allem in seinem Werk „Zrcadlo slavného Markrabství moravského“/Spiegel der berühmten Markgrafschaft Mähren) war die landfremde Herkunft der Familie nicht allein ein diskriminierendes Element der Integration. Auch Familien, die in der Zeit der Entstehung von Paprockýs Werk durch die im Lande beheimatete Adelsgesellschaft eindeutig als einheimische oder zumindest vor einigen Generationen heimisch gewordene Geschlechter wahrgenommen wurden, bezeugen in den Legenden ihre fremde Herkunft, die sich auch im heraldischen Zeichen widerspiegelt. ${ }^{42}$ Als Beispiel kann an dieser Stelle zumindest auf die Slawata von Chlum (Herkunft aus dem Gebiet

Bewohner des Königreichs Ungarn auf Fürsprache des oben erwähnten [Herrn] als Bewohner dieser Markgrafschaft anzunebmen und durch diesen Landtag gemäß unserer althergebrachten Ordnung aus freiem Willen aufzunebmen. Dergestalt, dass Bekenntnisschreiben zum Landfrieden [nach der Notula vom obersten Schreiber ibnen ausgestellt] dem obersten Schreiber übergeben werden.

40 Tomáš Knoz/Thomas Winkelbauer, Geschlecht und Geschichte. Grablegen, Grabdenkmäler und Wappenzyklen als Quellen für das historisch-genealogische Denken des österreichischen Adels im 16. und 17. Jahrhundert, in: Joachim Bahlcke/Arno Strohmeyer (Hg.), Die Konstruktion der Vergangenheit. Geschichtsdenken, Traditionsbildung und Selbstdarstellung im frühneuzeitlichen Ostmitteleuropa (Zeitschrift für historische Forschung, Beiheft 29), Berlin 2002, S. 129-178.

41 Zur Problematik des Schlosses als Ausdrucksmittel der (fürstlichen) Macht vgl. u. a. Matthias Müller, Das Schloss als Bild des Fürsten. Herrschaftliche Metaphorik in der Residenzarchitektur des Alten Reichs (1470-1618), Göttingen 2004.

42 Irena HrabĚtová, Erbovní pověsti v českých spisech Bartoloměje Paprockého z Hlohol [Wappenlegenden in den tschechischen Schriften des Bartoloměj Paprocký z Hlohol] (Opera Universitatis Masarykianae Brunensis, Facultas philosophica 291), Brno 1992. 
der Sau/Save und Drau/Drave, im Wappen durch drei Pflüge symbolisiert) und der Žerotín (Herkunft aus Russland, in der Heraldik symbolisiert durch einen schwarzen Löwen als angebliches ursprüngliches russisches Wappen) verwiesen werden. ${ }^{43}$ In beiden Fällen besitzt auch der integrative Bestandteil, repräsentiert durch den Text über den Dienst der Ahnen für das Geschlecht des böhmischen Herrschers/mährischen Landesherrn, große Bedeutung.

Am Beispiel der Präsentation des Žerotíner Familienmythos lässt sich zugleich die Dynamik und expressive Pluralität seiner symbolischen Form demonstrieren. Die Gründungslegende, die wir bei Paprocký finden, führte in den Sechzigerjahren des 17. Jahrhunderts der jesuitische Historiograf Georg Crugerius und schließlich in den Achtzigerjahren des 17. Jahrhunderts Franziskus Calin aus Marienberg fort. Calin kommuniziert mit seinem allgemeiner gehaltenen Stil durch drei Formen, die in einer gegenseitigen Beziehung stehen: dem majestätischen handschriftlichen Buch mit textlicher Narration, der narrativen Bildbegleitung (bedeutende Ereignisse aus der Geschichte der Familie Žerotín, symbolische Idealporträts) sowie heraldisch-genealogischen Schemata. Bei der zweiten Form handelt es sich um das gedruckte Buch, das den linguistischen Text akzentuiert und völlig visuelle Bestandteile außer Acht lässt. Die dritte Form wiederum bildet die große genealogische Wandkarte, die sich auf die visuellen Elemente des Familienmythos konzentriert. Sofern es um die interpretatorische Ebene geht, lassen sich in Calins Auffassung der Žerotíner Legende einige bedeutende Tatsachen ausmachen, die die Integration des fremden Adels im Lande charakterisieren. Calin entwickelt das grundlegende, bei Paprocký zur Anwendung gebrachte Prinzip weiter (Repräsentanten des fremden/russischen Adels kommen in die böhmischen Länder und integrieren sich hier mithilfe des Dienstes für den Landesherrn), er stärkt jedoch die erwähnten symbolischen Formen dieses Inhalts. Wichtig ist die Akzentuierung der dauerhaften Treue gegenüber dem Herrscher, die die „Untreue“ gegenüber dem katholischen Glauben aufhebt (Karl d. Ä. von Žerotín kommen als Nichtkatholik, der seinem katholischen Landesherrn die Treue erweist, vielleicht noch größere Verdienste zu als einem laxen Katholiken). Das Adelsgeschlecht der Žerotíner kann sich somit im Zeitraum nach der Konvertierung der Angehörigen seines Zweiges in Groß Ullersdorf (Velké Losiny) auf symbolischer Ebene als treue katholische Familie rehabilitieren, was wiederum auf die verschiedenen Typen der rechtlichen Integration seiner Angehörigen zurückwirkt. Im Grunde genommen handelt es sich um eine ähnliche Bindung wie im Falle der Beherrschung der tschechischen Sprache als symbolischer linguistischer Form bei Kardinal Franz von Dietrichstein, was diesem die rechtliche Integration im mährischen politischen bzw. Landtagsmilieu um 1600 gestattet. $^{44}$

43 Tomáš Knoz, Středověký původ moravské šlechty v Zrcadle Bartoloměje Paprockého [Der mittelalterliche Ursprung des mährischen Adels im Spiegel des Bartoloměj Paprocký], in: Tomáš Borovský/Libor Jan/Martin Wihoda (Hg.), Ad vitam et honorem. Profesoru Jaroslavu Mezníkovi přátelé a žáci k pětasedmdesátým narozeninám, Brno 2003, S. 149-166.

44 Die Handschrift des genealogischen Buches der Žerotíner aus der Feder Franz Calins von Marienberg, bzw. des Georg Crugerius, zu dem auch eine genealogische Wandkarte gehört, befindet sich in deren Familienarchiv. Zemský archiv Opava, pracoviště Olomouc, Rodinný archiv Žerotínů, kniha č. 5 [Landesarchiv Troppau, Arbeitsstelle Olmütz, Familienarchiv der Žerotíner, Buch Nr. 5; ebd., Karte Nr. 1]. Das genealogische Buch existiert darüber hinaus auch in gedruckter Form, mit einfachen Wappenausführungen und Abbildungen. Dominicus Franciscus Calin von Marienberg, Virtus Leonina, Viennae (1683) [Exemplar in der Mährischen Landesbibliothek, Sign. St 3-1239]; vgl. KNoz, Karel starší ze Žerotína (wie Anm. 36), S. 25-33. 
Die symbolische Form betonte nicht nur einmal die historische Breite bzw. den Reichtum der Verbindung des Geschlechts mit dem Lande mithilfe der Präsentation der familiären Verbindungen und der Heiratsstrategie. Sofern wir im Milieu der Žerotíner verbleiben, lässt sich dies mit Unterstützung des heraldischen und emblematischen Programms belegen, das die Žerotíner zwischen den Siebziger- und Neunzigerjahren des 16. Jahrhunderts an den Hofarkaden bzw. in den Interieurs der Familiensäle ihrer Schlösser in Namiest und Rossitz (Rosice) sichtbar zur Geltung brachten. ${ }^{45}$ Für gewöhnlich ist es so, dass die Struktur dieser symbolischen Programme vom italienischen Milieu möglicherweise mit Unterstützung des Hofprogrammes der Herren von Salamanca (heute Schloss Porcia) in der kärntnerischen Stadt Spittal an der Drau nach Mitteleuropa transformiert wurde. ${ }^{46}$ Das ikonologische und emblematische Programm expliziert die familiären Tugenden der Žerotíner, und mithilfe der Wappen verwandter Familien (z. B. der Herren von Leipa/Lípa, Lomnitz/ Lomnice und Sternberg/Šternberk) greifen diese Tugenden in die Landschaft der mährischen Aristokratie ein. Die kommunikative Achse zu diesen Programmen stellt dabei die Bildung der familiären genealogisch-heraldischen Karte dar, die sich auf Exzerpte aus Archiven und Forschungen im Milieu der sepulkralen bzw. diplomatischen Denkmäler stützt, zugleich aber auch in den rechtlichen Normen der mährischen Landesordnungen bzw. in symbolischen Texten über die Rolle des Adels - etwa in den bereits erwähnten Werken des Bartholomäus Paprocký - ihre Reflexion findet. ${ }^{47}$

Die angedeuteten Herangehensweisen sind in den alternativen Formen auch für zahlreiche weitere Repräsentanten aus dem aristokratischen Milieu typisch. Im Falle

Das Schloss des Adeligen in der Hochrenaissance verkörperte bei Weitem keinen reinen Ort luxuriösen Wohnens seiner Familie, ein Verwaltungs- und Gerichtszentrum des Dominiums oder letztlich gar ausschließlich das wirtschaftliche Zentrum der Herrschaft und des Großguts. Die architektonische Gestalt des Schlosses war zugleich Ausdruck des adeligen Lebensstils, sie traf eine Aussage über die Geschichte seines Geschlechts, seine gesellschaftliche Stellung, Bildung und persönliche Eigenschaften. Mithilfe architektonischer und künstlerischer Mittel lieferte es dem eingeweihten Besucher ein wichtiges Zeugnis, das er dann bei der Begegnung mit dem Schlossherrn gut verwenden konnte. Es verkörperte eine Art geschriebenes Buch, anders freilich als in der Schriftsprache, für gebildete und adelige Personen der Hochrenaissance jedoch in gleichem Maße verständlich. Zugleich wurde es mithilfe zahlreicher in der Schlossbibliothek aufbewahrter Schriften geformt. Für die gedanklichen Schemata der Zeit des Manierismus war die Verbindung von Wort und Bild eine der natürlichsten und geläufigsten Herangehensweisen. Vgl. Knoz, Karel starší ze Žerotína (wie Anm. 36), S. 151-166; Ders., Renesance a manýrismus na zámku v Rosicích [Renaissance und Manierismus im Schloss zu Rossitz], Rosice 1996, S. 45-59.

46 Erich Hubala, Die Baukunst der mährischen Renaissance, in: Ferdinand Seibt (Hg.), Renaissance in Böhmen, München 1985, S. 114-167, hier v. a. S. 155; Renate WagneRRieger/Ingeborg Mitsch, Das Schloss Spittal an der Drau in Kärnten (Studien zur österreichischen Kunstgeschichte 3), Wien 1962.

47 Zemský archiv Opava, pracoviště Olomouc, Rodinný archiv Žerotínů, mapa č. 3 [Landesarchiv Troppau, Arbeitsstelle Olmütz, Familienarchiv der Žerotíner, Karte Nr. 3]; KNOz, Renesance a manýrismus (wie Anm. 45), S. 60-79; Ders., Erinnerungskultur in der Gestaltung der mährischen Renaissanceschlösser (1550-1650). Grenzüberschreitungen von Zeit, Raum, Konfession, Stand und künstlerischem Ausdruck, in: Walter Schmitz/Jens Stüben/Matthias Weber (Hg.), Adel in Schlesien, Bd. 3: Adel in Schlesien und Mitteleuropa. Literatur und Kultur von der Frühen Neuzeit bis zur Gegenwart (Schriften des Bundesinstituts für Kultur und Geschichte der Deutschen im östlichen Europa 48), München 2013, S. 123-155. 
der Liechtensteiner findet dies in ausgeprägter Form in deren familiärer Doppelhochzeit mit den Erben Johann Schemberas von Boskowitz auf Butschowitz seinen Ausdruck. Die Liechtensteiner übernehmen die Besitzungen der Boskowitzer und auch deren Familienlegenden und symbolische Programme, die z. B. in Butschowitz auch weiterhin eine grundlegende Rolle spielen. Die architektonische Form und der symbolische künstlerisch geformte Inhalt in der liechtensteinischen Phase der Schlossumbauten in Butschowitz knüpfen an die Boskowitzer Phase an (und ähnlich ist dies auch im Falle der liechtensteinischen Anknüpfung an die Programme der Herren von Kunowitz in Ungarisch Ostra/Uherský Ostroh). Die Liechtensteiner ließen am Ende die heraldischen Symbole der Boskowitzer in ihr Wappen einfließen. Die Bedeutung der Familientradition der Boskowitzer für die liechtensteinische Tradition wird in der Tatsache offenkundig, dass den Sarg Katharinas von Boskowitz, der Gemahlin Fürst Maximilians von Liechtenstein und Mitbegründerin der Paulaner-Kirche mit dem liechtensteinischen Familiengrab, explizit Boskowitzer heraldische Symbole zieren und andererseits hier die heraldischen Symbole der Liechtensteiner vollkommen fehlen. Die Interpretation dieser Tatsachen erweist sich bei einer Absenz der relevanten Quellen selbstverständlich als ein wenig problematisch, auf der anderen Seite kann man sich z. B. auf die einen gewissen Streit um das symbolische (und in Gestalt des Boskowitzer Stadthauses in Olmütz auch konkrete) Erbe der Boskowitzer aufzeigende Korrespondenz stützen, zu dem es nach dem Tode Karls von Liechtenstein im Jahre 1627 zwischen Liechtensteinern und Žerotínern kam. Wie die genealogischen Karten der Žerotíner belegen, waren auch diese mehrfach mit den Herren von Boskowitz verwandt und konnten somit Anspruch auf deren symbolisches Erbe erheben.

Weder Liechtensteiner noch Žerotíner wurden vermutlich um 1600 in Mähren als Repräsentanten des landfremden Adels wahrgenommen, dessen ungeachtet festigte und multiplizierte das Boskowitzer Erbe zumindest in symbolischer (und wohl auch rechtlicher) Form deren Bindung an das Land zur Genüge. ${ }^{48}$ Während die Žerotíner Familienlegende bei Paprocký auf die Herkunft aus Russland zielt, hat der Autor die Familiengeschichte der Liechtensteiner wesentlich reduziert. Da er jedoch am Ende der autochthon aufgefassten Wappenlegende der Boskowitzer die Rolle der „schönen Jungfrauen von Boskowitz" gleichsam als Erbe des reichen Johann Schembera unterstrich, antizipierte er so die Bedeutung ihrer zukünftigen Heirat. ${ }^{49}$ Die Liechtensteiner haben durch die Heirat ihren Grundbesitz in Mähren vervielfacht und sie begannen mit der Verlagerung des Eigentumskerns ihrer Familienbesitzungen von Österreich nach Mähren. Noch nach Jahrhunderten werden sie auf die Tatsache verweisen, dass der Familienbesitz im Lande durch die Heirat mit den Töchtern Johann Schemberas von Boskowitz zunahm - keineswegs jedoch durch den aus den Konfiszierungen nach

48 Tomáš KnOz, Erinnerungsorte der Liechtenstein. Einleitende Thesen, in: Liechtensteinische Erinnerungsorte in den böhmischen Ländern, hrsg. von der LiechtensteinischTschechischen Historikerkommission (Veröffentlichungen der LiechtensteinischTschechischen Historikerkommission 1), Vaduz 2012, S. 11-32; Ders., Die Liechtensteinischen Schlossresidenzen im Kontext der mährisch-österreichischen Renaissance und des Manierismus, Schloss Rabensburg, in: Die Liechtenstein und die Kunst, hrsg. von der Liechtensteinisch-Tschechischen Historikerkommission (Veröffentlichungen der Liechtensteinisch-Tschechischen Historikerkommission 3), Vaduz 2014, S. 87-135; Kateřina Dufková, Jan Šembera Černohorský z Boskovic. Moravský Petr Vok [Johann Schembera Černohorský von Boskowitz. Der mährische Petr Wok] (Velké postavy českých dějin 16), Praha 2014, v. a. S. 163-166.

49 PaprockÝ, Zrcadlo slavného Markrabství moravského (wie Anm. 11), fol. 97r-103v (Herren von Boskowitz), 143 ${ }^{\mathrm{r}}-145^{\mathrm{r}}$ (Herren von Liechtenstein). 


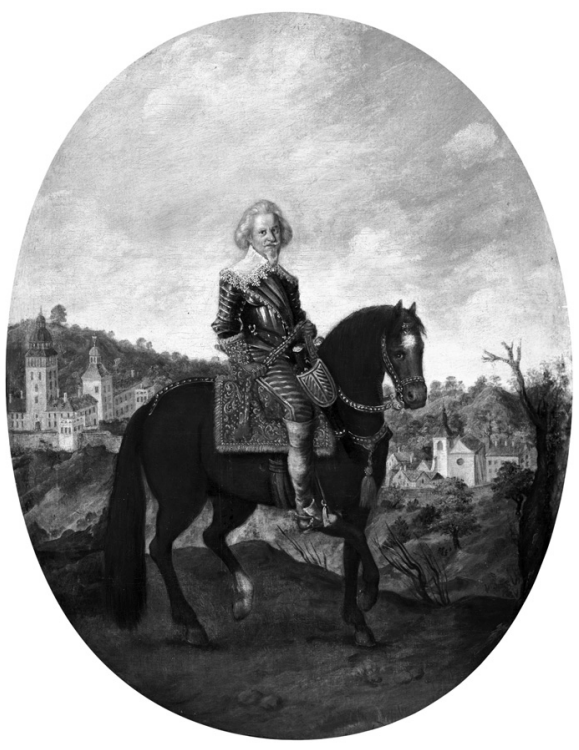

Abb. 5: Gundaker von Liechtenstein mit dem Schloss Mährisch Kromau.

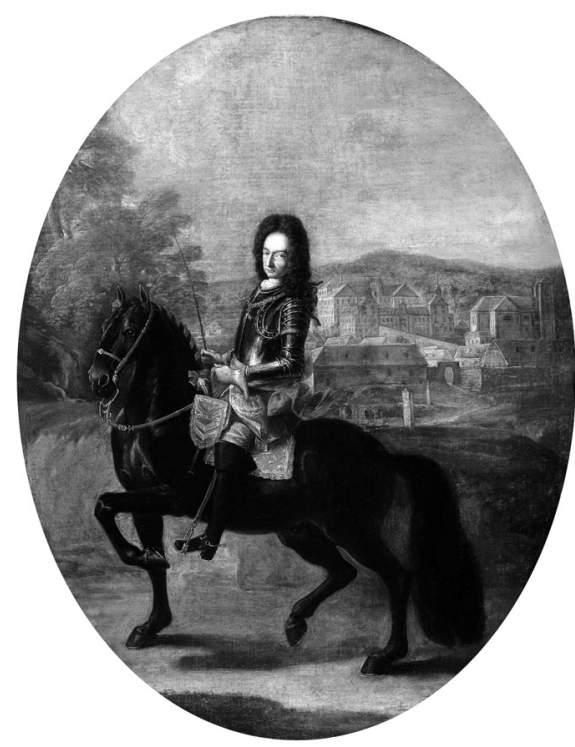

Abb. 6: Anton Florian von Liechtenstein mit dem Schloss Feldsberg.

der Schlacht am Weißen Berg erfolgten Gewinn. Sofern es um die rechtliche Ebene geht, ist es offenkundig kein Zufall, dass ein an die Heirat mit Anna Maria von Boskowitz anknüpfender qualitativer Sprung in der Stellung Karls von Liechtenstein dessen Ernennung zum mährischen Landeshauptmann bedeutete; erst später, mit dem Gewinn des Fürstentitels, tritt er aus dem Milieu des Landes heraus und die Liechtensteiner beginnen so schrittweise eine eigene Staatsräson zu formen. ${ }^{50}$

\section{Schlussbemerkungen: Der Adel zwischen Land und Herrscher}

Die oben beschriebene Integration der Angehörigen des landfremden Adels definiert bei Weitem nicht alle zeitgenössischen Varianten und Möglichkeiten des angezeigten Prozesses. In dieser Hinsicht wäre es notwendig, Personen zu differenzieren, die mit der eindeutigen Absicht nach Mähren kamen, sich auch in die politischen und administrativen Organe des Landes zu integrieren (z. B. Stanislav Pavlovsky, Franz von Dietrichstein, Ladislav von Lobkowitz, Franz von Kolowrat), andere Adelige begriffen diesen Typ der Integration als erste Stufe auf dem Wege zu einer anspruchsvolleren Karriere (u. a. Albrecht von Wallenstein, Louis Raduit de Souches), wiederum andere verbanden den Erwerb von Grundbesitz in Mähren in keiner Weise mit der politischen Integration in der Adelsgesellschaft des Landes oder erst in nachfolgenden Generationen (etwa Rombaldo Collalto, Johann Baptist von Werdenberg). Ein anderes Modell zeigt sich darüber hinaus, sofern wir nicht einzelne Personen, sondern zum Beispiel

50 Evelin Oberhammer, „Viel ansehnliche Stuck und Güeter“. Die Entwicklung des fürstlichen Herrschaftsbesitzes, in: Dies. (Hg.), Der ganzen Welt ein Lob und Spiegel. Das Fürstenhaus Liechtenstein in der frühen Neuzeit, Wien/München 1990, S. 33-45; Dufková, Jan Šembera Černohorský z Boskovic (wie Anm. 48), S. 163-166. 
die Angehörigen einer Familie über mehrere Generationen und Familienlinien verfolgen. Dies gilt mitunter ebenso für die Integration eines Adeligen sowie seiner aus Angehörigen des Nieder- und weniger vermögenden Adels sich zusammensetzenden Klienten- und Beamtenschicht (z. B. die Illésházy und Pálffy von Erdöd gemeinsam mit einigen kleineren Familien, die in Ostmähren eine spezifische „Subkultur" der ungarischen Immigration bildeten - keineswegs unähnlich der „österreichischen Subkultur“ an der mährisch-österreichischen Grenze und in einigen Situationen der „schlesischen Subkultur“ an der schlesisch-mährischen Grenze).

Mit Blick auf die untersuchte Kommunikation zwischen rechtlicher und symbolischer Norm spielt auch die Fokussierung des Adeligen auf den Herrscher (mitunter die Integration des Adels am Herrscherhof) eine wichtige Rolle. Wenngleich dieser Typ der Integration in der Regel zuweilen als Konkurrenz gegenüber der Integration zum Land präsentiert wird (etwa in einer konfessionell-politischen und simplifizierenden Auffassung des Verhältnisses zwischen Ständewesen im Land und herrscherlichem Absolutismus), muss dies nicht in allen Fällen so sein. Der Herrscher war zugleich auch Landesherr in Mähren, mitunter das Haupt eines breiteren, die Habsburgermonarchie als eine Art „Super-Land“ integrierenden Ganzen. Die erste Auffassung finden wir zum Beispiel auch in den Rechtstexten Karls d. Ä. von Žerotín, in denen der Autor um das Jahr 1608 die Orientierung auf Erzherzog Matthias von Habsburg verteidigte oder als er um 1619 die Hinwendung zu Friedrich von der Pfalz ablehnte. Die symbolischen ikonografischen und narrativen „Herrscherzyklen“ als spezifisches Element des „sacrum in profanum“ waren im Milieu der Ära vor der Schlacht am Weißen Berg in jenen Milieus gegenwärtig, deren Träger so oder so im ständischen Milieu des Landes integriert waren (z. B. das Butschowitz Johann Schemberas von Boskowitz, das Fulnek der Herren Mol von Modřelice, das Ratschitz/Račice des Hanusch Haugwitz von Biskupitz).

Die zweite Auffassung wird gut sichtbar in Fällen, in denen als Repräsentant der in mehreren Ländern Güter besitzende Adelige erscheint, was die Identifikation mit der sich konstituierenden Monarchie als größerem - ähnlich wie im Falle des Landes territorial definierten - Ganzen repräsentierte oder aber unmittelbar bei Aristokraten, die am Herrscherhof agierten. Als einziges, stellvertretend für alle anzusehendes Beispiel kann der Kreis Johann Baptists von Werdenberg erwähnt werden, dessen Familie aus dem norditalienischen Milieu stammte und sich zuerst in der Steiermark integrierte und letztlich praktisch in allen Ländern der Habsburgermonarchie. Im Falle des österreichischen Hofkanzlers von Werdenberg lässt sich darüber hinaus dieser spezifisch hierarchische Typ der Verschmelzung mit dem Herrscher/Gott auf dem Höhepunkt einer imaginären Pyramide mithilfe verschiedener Quellentypen verfolgen. Dies gilt vor allem für die von Werdenberg herausgegebenen Rechtsnormen, die „herrscherlich“ zentral für die Herrschaften in verschiedenen Ländern galten, heraldische Zeichen, die die Herleitung der Macht ihrer Träger von jener des Herrschers zeigen, komplizierte architektonische und bildkünstlerische Gesamtheiten, die in die manieristische Grabkapelle münden, die die Versachlichung des dem Herrscher treu ergebenen Adeligen zum Ausdruck bringen, bis hin zum damit zusammenhängenden narrativen Text der Grabpredigt des höfischen Barnabiter-Predigers Florentius Schilling am toten Körper des Kanzlers: Hier liegt begraben Johann Baptist, / Ein Grav von Verdenberg Er ist. / Der war dem Kayser lieb und werth, /Sein Seel hat Gott zu sich begebrt. /Hier liegt sein Leib, laß ibn im Rub, /Er gehört dem Kayser und Gott auch zu. ${ }^{51}$

51 Florentius Schilling, Todten-Gerüst, das ist Wolgegründte Ehren-Gedächtnuß hochadelicher Cavalliern, Herren und Frauen, Deren Hoch-Adeliches Herkommen, Christlöbl. Thaten und seel. Tod in unterschiedlichen Leich-Predigten mit angenehmen 
Anhang

Die Integration der reichsten Vertreter des mährischen Adels für das Jabr 1644

Quelle der Angaben über die Adeligen entsprechend der Zahl der Untertanen: FrANTišEk MatĚJek, Bílá hora a moravská feudální společnost [Die Schlacht am Weißen Berg und die mährische Feudalgesellschaft], in: Československý časopis historický 22 (1974), S. 92.

Legende:

1 - ursprünglicher mährischer Adel

2 - Einwanderung im Mittelalter

3 - Einwanderung in der Zeit vor der Schlacht am Weißen Berg (1526-1620)

4 - Einwanderung in der Zeit nach der Schlacht am Weißen Berg (1620-1644)

\begin{tabular}{|c|c|c|c|c|c|c|c|}
\hline & \multirow[t]{2}{*}{ Adeliger } & \multirow{2}{*}{$\begin{array}{l}\text { Zahl der } \\
\text { Unter- } \\
\text { tanen }\end{array}$} & \multicolumn{4}{|c|}{ Zuzug im Lande } & \multirow[t]{2}{*}{ Anmerkung } \\
\hline & & & 1 & 2 & 3 & 4 & \\
\hline 1. & $\begin{array}{l}\text { Karel } \\
\text { Eusebius von } \\
\text { Liechtenstein }\end{array}$ & 9349 & & & & & $\begin{array}{l}\text { Das ursprünglich aus dem Reich } \\
\text { stammende Geschlecht kam im } 13 . \\
\text { Jahrhundert aus Österreich nach } \\
\text { Mähren. Über Jahrhunderte hin- } \\
\text { weg integrierte es sich politisch } \\
\text { und kulturell im Lande und er- } \\
\text { blickte in Mähren sein Hinterland. }\end{array}$ \\
\hline 2. & $\begin{array}{l}\text { Maximilian } \\
\text { von } \\
\text { Dietrichstein }\end{array}$ & 5628 & & & & & $\begin{array}{l}\text { Das Geschlecht kam in der } 2 . \\
\text { Hälfte des 16. Jahrhunderts nach } \\
\text { Mähren. Inkolat. Ab der zweiten } \\
\text { Generation integrierte es sich poli- } \\
\text { tisch und kulturell im Lande. }\end{array}$ \\
\hline 3. & $\begin{array}{l}\text { Gundaker } \\
\text { von } \\
\text { Liechtenstein }\end{array}$ & 3906 & & & & & $\begin{array}{l}\text { Siehe 1. Der Zweig Gundakers } \\
\text { etablierte sich in Mähren erst nach } \\
\text { der Schlacht am Weißen Berg. }\end{array}$ \\
\hline 4. & $\begin{array}{l}\text { Maximilian } \\
\text { von } \\
\text { Liechtenstein }\end{array}$ & 2204 & & & & & $\begin{array}{l}\text { Siehe 1. Maximilian kam in den } \\
\text { Neunzigerjahren des 16. Jahrhun- } \\
\text { derts nach Mähren. Mit Blick auf } \\
\text { den Ursprung der Familie benö- } \\
\text { tigte er kein Inkolat. }\end{array}$ \\
\hline
\end{tabular}

Verfassungen der Welt zum Tugend-Spiegel vorgestellet worden [...], Sulzbach 1681 (Exemplar Universitätsbibliothek Wien, Sign. I-188.128); Franz M. Eybl, Predigt Sammlung - Literaturprogramm. Zu Florentius Schillings Predigtsammlung „Amaradulcis“ (1658), in: Jean-Marie Valentin (Hg.), Gegenreformation und Literatur. Beiträge zur interdisziplinären Erforschung der katholischen Reformbewegung, Amsterdam 1979, S. 299-346; Tomáš Knoz, Todten Gegrüßt. Dobrá smrt ctnostného šlechtice v pohřebních kázáních Dona Florentia Schillinga [Todten Gegrüßt. Der gute Tod des ehrwürdigen Adeligen in Grabpredigten Don Florentio Schillings], in: Sborník prací filozofické fakulty brněnské univerzity C/49 (2002), S. 119-134. 


\begin{tabular}{|c|c|c|c|}
\hline 5. & $\begin{array}{l}\text { Lev Wilhelm } \\
\text { von Kaunitz }\end{array}$ & 2085 & $\begin{array}{l}\text { Alteingesessenes mährisches Ge- } \\
\text { schlecht, in der ganzen Geschichte } \\
\text { politisch und kulturell in Mähren } \\
\text { integriert. }\end{array}$ \\
\hline 6. & $\begin{array}{l}\text { Wenzel } \\
\text { Eusebius von } \\
\text { Lobkowitz }\end{array}$ & 1903 & $\begin{array}{l}\text { Alteingesessenes böhmisches Ge- } \\
\text { schlecht, das aus politischen Grün- } \\
\text { den zu Beginn des 17. Jahrhunderts } \\
\text { nach Mähren kam und das Land } \\
\text { Mitte des 17. Jahrhunderts wieder } \\
\text { verließ. Im Land als fremdes Ele- } \\
\text { ment wahrgenommen, trotz der } \\
\text { tschechischsprachigen Herkunft } \\
\text { und des nicht erforderlichen Inko- } \\
\text { lats. }\end{array}$ \\
\hline 7. & $\begin{array}{l}\text { Joachim } \\
\text { Andreas } \\
\text { Slawata von } \\
\text { Chlum }\end{array}$ & 1681 & $\begin{array}{l}\text { Alteingesessenes mährisches Ge- } \\
\text { schlecht, wenn auch später vor- } \\
\text { nehmlich mit Böhmen verbunden. } \\
\text { In der Überlieferung wird die } \\
\text { Herkunft aus Ungarn im Mittel- } \\
\text { alter angegeben, wobei der Weg } \\
\text { nach Mähren führte. }\end{array}$ \\
\hline 8. & $\begin{array}{l}\text { Balthasar von } \\
\text { Žerotín }\end{array}$ & 1565 & $\begin{array}{l}\text { Alteingesessenes mährisches Ge- } \\
\text { schlecht. In den Legenden wird die } \\
\text { Herkunft aus Russland im Mittel- } \\
\text { alter nach Mähren tradiert. Wäh- } \\
\text { rend der gesamten Geschichte im } \\
\text { Lande politisch und kulturell } \\
\text { etabliert. }\end{array}$ \\
\hline 9. & $\begin{array}{l}\text { Johann } \\
\text { Burian } \\
\text { Žampach von } \\
\text { Pottenstein }\end{array}$ & 1541 & $\begin{array}{l}\text { Böhmisches Geschlecht, in der } \\
\text { zweiten Hälfte des 16. Jahrhunderts } \\
\text { nach Mähren eingewandert, ohne } \\
\text { Erfordernis des Inkolats. Im } \\
\text { Lande in der ersten Generation } \\
\text { politisch, später auch kulturell } \\
\text { etabliert. }\end{array}$ \\
\hline 10. & $\begin{array}{l}\text { Julius von } \\
\text { Salm }\end{array}$ & 1535 & $\begin{array}{l}\text { Ursprünglich ein deutsches Ge- } \\
\text { schlecht, über Böhmen in der Zeit } \\
\text { nach der Schlacht am Weißen Berg } \\
\text { eingewandert (deshalb auch kein } \\
\text { Inkolat erforderlich), politisch und } \\
\text { schrittweise in hohem Maße auch } \\
\text { kulturell integriert. }\end{array}$ \\
\hline
\end{tabular}




\begin{tabular}{|c|c|c|c|}
\hline 11. & $\begin{array}{l}\text { Johann } \\
\text { Baptist von } \\
\text { Werdenberg }\end{array}$ & 1480 & $\begin{array}{l}\text { Ursprünglich aus Italien stam- } \\
\text { mend, über die Steiermark und } \\
\text { Österreich nach Mähren einge- } \\
\text { wandert, daher als österreichisches } \\
\text { Geschlecht wahrgenommen bzw. } \\
\text { als Hofadel. Im Lande in der } \\
\text { zweiten Generation politisch inte- } \\
\text { griert. }\end{array}$ \\
\hline 12. & $\begin{array}{l}\text { Franz von } \\
\text { Magni }\end{array}$ & 1463 & $\begin{array}{l}\text { Herkunft aus Italien (andernorts } \\
\text { aus Skandinavien). In der Zeit } \\
\text { vor der Schlacht am Weißen Berg } \\
\text { nach Mähren zugewandert, poli- } \\
\text { isch nach der Schlacht am Weißen } \\
\text { Berg integriert (Landeshaupt- } \\
\text { mann), schrittweise auch kulturell. } \\
\text { In gewissem Umfang als landfremd } \\
\text { wahrgenommen. }\end{array}$ \\
\hline 13. & $\begin{array}{l}\text { Ferdinand } \\
\text { Leopold von } \\
\text { Náchod }\end{array}$ & 1415 & $\begin{array}{l}\text { Alteingesessenes Rittergeschlecht, } \\
\text { vor und nach der Schlacht am } \\
\text { Weißen Berg zunehmend, Genera- } \\
\text { tionen später voll im Lande inte- } \\
\text { griert. }\end{array}$ \\
\hline 14. & $\begin{array}{l}\text { Nikolaus } \\
\text { Forgács von } \\
\text { Ghymes }\end{array}$ & 1260 & $\begin{array}{l}\text { Ungarisches Adelsgeschlecht, im } \\
\text { Lande Inkolat vor der Schlacht am } \\
\text { Weißen Berg. Lediglich teilweise } \\
\text { im Lande integriert. }\end{array}$ \\
\hline 15. & $\begin{array}{l}\text { Franz Adam } \\
\text { von } \\
\text { Waldstein }\end{array}$ & 1175 & $\begin{array}{l}\text { Alteingesessenes Geschlecht, ein } \\
\text { Zweig seit alters her im Lande } \\
\text { ansässig. Der betreffende Zweig } \\
\text { wanderte aus Böhmen vor der } \\
\text { Schlacht am Weißen Berg zu. In } \\
\text { den Legenden wird seine böhmi- } \\
\text { sche Herkunft betont. Kein Inko- } \\
\text { lat erforderlich. Politisch und kul- } \\
\text { turell im Lande integriert. }\end{array}$ \\
\hline
\end{tabular}

